\title{
Understanding Governance of Early Childhood Development and Education Systems and Services in Low-Income Countries
}

Pia Rebello Britto, Hirokazu Yoshikawa, Jan Van Ravens, Liliana A. Ponguta, Soojin S. Oh, Roland Dimaya, Richard C. Seder Office of Research Working Paper 


\section{INNOCENTI WORKING PAPERS}

UNICEF Office of Research Working Papers are intended to disseminate initial research contributions within the programme of work, addressing social, economic and institutional aspects of the realization of the human rights of children.

The findings, interpretations and conclusions expressed in this paper are those of the authors and do not necessarily reflect the policies or views of UNICEF.

The text has not been edited to official publications standards and UNICEF accepts no responsibility for errors.

Extracts from this publication may be freely reproduced with due acknowledgement. Requests to utilize larger portions or the full publication should be addressed to the Communication Unit at florence@unicef.org.

For readers wishing to cite this document we suggest the following form:

Rebello Britto, P., Yoshikawa, H., Van Ravens, J., Ponguta, L. A., Oh, S.S., Dimaya, R., Seder, R.C. (2013). Understanding Governance of Early Childhood Development and Education Systems and Services in LowIncome Countries, Innocenti Working Paper No.2013-07, UNICEF Office of Research, Florence.

(C) 2013 United Nations Children's Fund (UNICEF)

ISSN: 1014-7837 


\section{THE UNICEF OFFICE OF RESEARCH}

In 1988 the United Nations Children's Fund (UNICEF) established a research centre to support its advocacy for children worldwide and to identify and research current and future areas of UNICEF's work. The prime objectives of the Office of Research are to improve international understanding of issues relating to children's rights and to help facilitate full implementation of the Convention on the Rights of the Child in developing, middle-income and industrialized countries.

The Office aims to set out a comprehensive framework for research and knowledge within the organization, in support of its global programmes and policies. Through strengthening research partnerships with leading academic institutions and development networks in both the North and South, the Office seeks to leverage additional resources and influence in support of efforts towards policy reform in favour of children.

Publications produced by the Office are contributions to a global debate on children and child rights issues and include a wide range of opinions. For that reason, some publications may not necessarily reflect UNICEF policies or approaches on some topics. The views expressed are those of the authors and/or editors and are published in order to stimulate further dialogue on child rights.

The Office collaborates with its host institution in Florence, the Istituto degli Innocenti, in selected areas of work. Core funding is provided by the Government of Italy, while financial support for specific projects is also provided by other governments, international institutions and private sources, including UNICEF National Committees.

Extracts from this publication may be freely reproduced with due acknowledgement. Requests to translate the publication in its entirety should be addressed to: Communications Unit, florence@unicef.org.

For further information and to download or order this and other publications, please visit the website at www.unicef-irc.org.

\section{Correspondence should be addressed to:}

UNICEF Office of Research - Innocenti

Piazza SS. Annunziata, 12

50122 Florence, Italy

Tel: (+39) 05520330

Fax: (+39) 0552033220

florence@unicef.org

www.unicef-irc.org

This text has not been edited to official publication standards and UNICEF accepts no responsibility for errors. 


\section{UNDERSTANDING GOVERNANCE OF EARLY CHILDHOOD DEVELOPMENT AND EDUCATION SYSTEMS AND SERVICES IN LOW-INCOME COUNTRIES}

Pia Rebello Britto, ${ }^{a}$ Hirokazu Yoshikawa, ${ }^{\mathrm{b}}$ Jan Van Ravens, ${ }^{\mathrm{a}}$ Liliana A. Ponguta, ${ }^{\mathrm{a}}$ Soojin S. Oh,

Roland Dimaya, ${ }^{a}$ and Richard C. Seder ${ }^{c}$

a Yale University

${ }^{\mathrm{b}}$ Harvard Graduate School of Education

' University of Southern California

Abstract. This initial exploratory study examines the governance and finance of ECS in three countries using an in-depth qualitative approach. The methodologies and tools provide an innovative strategy built upon the literature of governance and finance to understand how to improve access, quality and equity of ECS. Cross-country analyses reveal key emerging trends in ECD systems governance at different levels and around crucial dimensions, including actors, coordination, policy architectures, and local-level perspectives. The findings of this study have implications for strengthening systems of global ECD systems research.

Keywords: Early childhood development, education, low-income countries, governance, social policy

Acknowledgements: We owe a debt of gratitude to the local study teams and partners in each of the three countries under study, in particular Natalia Mufel (Cambodia), Oscar Kadenge and Jane Mgabi-Mututa (Kenya), and Maliphet Soukhaseum and Jill Zarchin (Lao People's Democratic Republic). Without their coordination and cooperation, this study could not have been completed. (We also acknowledge the support of the EAPRO and ESARO UNICEF Regional Offices for the coordination of this study. We would like to acknowledge N. Shemrah Fallon for her editorial assistance in the production of this report.) Support for this study was provided by the UNICEF Office of Research through funding from the Bernard van Leer Foundation. 
TABLE OF CONTENTS

$\begin{array}{ll}\text { Acronyms } & 6\end{array}$

$\begin{array}{lr}\text { Executive summary } & 9\end{array}$

1. Introduction 10

1.1 What is Early Childhood Development (ECD)? 11

$\begin{array}{ll}\text { 1.2 What is governance of ECS? } & 11\end{array}$

$\begin{array}{lr}1.3 \text { Research questions } & 16\end{array}$

$\begin{array}{ll}\text { 2. Study methodology } & 17\end{array}$

$\begin{array}{lr}2.1 \text { Sampling framework } & 17\end{array}$

$\begin{array}{lr}2.2 \text { Instrumentation } & 19\end{array}$

$\begin{array}{lr}2.3 \text { Procedure } & 20\end{array}$

3. Study findings by country 22

$\begin{array}{lr}3.1 \text { Cambodia } & 22\end{array}$

$\begin{array}{ll}\text { 3.2 Lao People’s Democratic Republic } & 28\end{array}$

$\begin{array}{ll}3.3 \text { Kenya } & 35\end{array}$

4. Study findings: cross-country patterns 44

4.1 Who are the main actors in ECS and what are the implications for capacity building? 45

4.2 Dimensions of governance: horizontal and vertical coordination 46

4.3 Influence of policy on coordination function of governance 49

4.4 Local governance structures as a key lever for ECS improvement $\quad 50$

4.5 Role of beneficiaries in governance of ECS

$\begin{array}{ll}4.6 \text { Closing issues } & 53\end{array}$

$\begin{array}{lr}\text { References } & 59\end{array}$ 


\begin{tabular}{|c|c|}
\hline AACs & Area Advisory Councils \\
\hline BvL & Bernard van Leer Foundation \\
\hline CCWC & Commune Committee for Women and Children \\
\hline CCWCFP & Commune Chief Women and Children Focal Point \\
\hline CHEWs & Community Extension Health Workers \\
\hline CHWs & Community Health Workers \\
\hline $\mathrm{C}-\mathrm{IMCl}$ & Community-based Integrated Management of Childhood IIIness \\
\hline CORPs & Community Owned Resource Persons \\
\hline CPNs & Child Protection Networks \\
\hline CPS & Community Preschools \\
\hline CRC & Convention on the Rights of the Child \\
\hline CRDI & Cambodia Development Resource Institute \\
\hline CT-OVC & Cash Transfer Program for Orphans and Vulnerable Children \\
\hline DCO & District Child Officers \\
\hline$D \& D$ & Decentralization and Deconcentration \\
\hline DEB & District Education Board \\
\hline DEMIS & District education management and monitoring information systems \\
\hline DEO & District Officers of Education \\
\hline DH\&P & Department Hygiene \& Prevention \\
\hline DIC & Department of International Cooperation \\
\hline DICECE & District Centers for Early Childhood Education \\
\hline DMO & District Medical Officer \\
\hline $\mathrm{DMOH}$ & District Medical Officer of Heath \\
\hline DPHO & District Public Health Officer \\
\hline DPP & Department of Pre-School and Primary Education \\
\hline DQASO & District Quality Assurance Officers \\
\hline EAPRO & East Asia and the Pacific Regional Office \\
\hline ECCD & Early Childhood Care and Development \\
\hline ECCE & Early Childhood Care and Education \\
\hline ECD & Early Childhood Development \\
\hline ECDE & Early Childhood Development and Education \\
\hline ECE & Early Childhood Education \\
\hline ECS & Early Childhood Services \\
\hline EFA & Education for All \\
\hline EMIS & Education Management Information System \\
\hline EMOC & Emergency Obstetric Care \\
\hline EPI & Expanded Program for Immunization \\
\hline ESARO & Eastern and Southern Africa Regional Office \\
\hline ESDF & Education Sector Development Framework \\
\hline FBOs & Faith-Based Organizations \\
\hline FGD & Focus Group Discussion \\
\hline GDP & Gross Domestic Product \\
\hline
\end{tabular}




\begin{tabular}{|c|c|}
\hline GER & Gross Enrolment Ratio \\
\hline GNI & Gross National Income \\
\hline GoK & Government of Kenya \\
\hline HBP & Home-Based Programme \\
\hline HDI & Human Development Index \\
\hline HIV-AIDS & Human Immunodeficiency Virus Infection- Acquired Immunodeficiency Syndrome \\
\hline $\mathrm{IMCl}$ & Integrated Management of Childhood Illness \\
\hline INGO'S & International Non-governmental Organizations \\
\hline JICA & Japan International Cooperation Agency \\
\hline $\mathrm{KEPH}$ & Kenya Essential Package for Health \\
\hline KESSP & Kenya Sector Support Program \\
\hline KIE & Kenya Institute of Education \\
\hline LMIC & Low-and/or Middle- Income Countries \\
\hline LPDR & Lao People's Democratic Republic \\
\hline $\mathrm{MCHC}$ & Maternal Child Health Center \\
\hline MDG & Millennium Development Goals \\
\hline MoA & Ministry of Agriculture \\
\hline MoE & Ministry of Education \\
\hline MoEST & Ministry of Education, Science and Technology \\
\hline MoEYS & Ministry of Youth and Sports \\
\hline MoF & Ministry of Finance \\
\hline MoGCSD & Ministry of Gender, Children and Social Development \\
\hline MoGCD\&SS & Ministry of Gender, Children, Development and Social Services \\
\hline $\mathrm{MoH}$ & Ministry of Health \\
\hline MoHA & Ministry of Home Affairs \\
\hline Mol & Ministry of Interior \\
\hline MolC & Ministry of Information and Communications \\
\hline MoJ & Ministry of Justice \\
\hline MoLG & Ministry of Local Government \\
\hline MoP & Ministry of Planning \\
\hline MoPI & Ministry of Planning and Investment \\
\hline MoPND & Ministry of Planning and National Development \\
\hline MoRPW & Ministry of Roads and Public Works \\
\hline MoW & Ministry of Works \\
\hline MoWA & Ministry of Women Affairs \\
\hline MTL & Mother Team Leader \\
\hline NACECE & National Center for Early Childhood Education \\
\hline $\mathrm{NaECD}$ & National Committee on ECD \\
\hline NCCS & National Council for Children's Services \\
\hline NGOs & Non-governmental organization \\
\hline NSEDP & National Socio-Economic Development Plan \\
\hline PES & Provincial Education Service \\
\hline PHD & Provincial Health Department \\
\hline POE & Provincial Office of Education \\
\hline
\end{tabular}




$\begin{array}{ll}\text { POWA } & \text { Provincial Office of Women's Affairs } \\ \text { SCN } & \text { Save the Children Norway } \\ \text { SitAn } & \text { Situation Analysis } \\ \text { SPS } & \text { State Preschools } \\ \text { UN } & \text { United Nations } \\ \text { UNDP } & \text { United Nations Development Programme } \\ \text { UNESCO } & \text { United Nations Educational, Scientific and Cultural Organization } \\ \text { UNICEF } & \text { United Nations Children's Fund } \\ \text { VEDCs } & \text { Village Education Development Committees } \\ \text { WHO } & \text { World Health Organization }\end{array}$




\section{EXECUTIVE SUMMARY}

Over the past decade, early childhood development and education (ECDE) has received increasing attention. This has led to an influx of scientific, macroeconomic, and rights-based evidence, supporting the importance of equitably implementing quality ECDE programmes and services. Despite the increase in evidence, young children in the developing world still bear the greatest burden of poverty, disease, violence, and risk factors (UNICEF, 2012). Recent research suggests that equitable access to quality early childhood services (ECS) can reduce the impact of risk factors and improve outcomes (Engle et al., 2011).

Most work on improving equity, access and quality of early childhood development (ECD) has examined it at the service level (Britto, Engle \& Super, 2013). However, the support, sustainability and scalability of those services are provided by structural systems. In turn, the governance of those systems is vital to their success. Although examination of governance of public systems is a longstanding focus in education, health, and other realms of social policy, it is a relatively novel subject of study for ECD. In this study, we sought to identify key governance mechanisms of health, education, and protection systems that are linked with improving equity, access, and quality of ECD in Cambodia, Laos and Kenya.

We employed a mixed-methods phased design (semi-structured interviews, focus group discussions, examination of national policy documents) with country level adaptations. Sampling for the study considered geographic sampling of countries and, within country, regions or provinces that represented advantaged and disadvantaged areas with respect to child well-being and ECS access indicators. Policies, sectors, systems and services were selected according to predefined selection criteria and identified in partnership with in-country counterparts. Sampling of respondents included systems (individuals working in the sectors of health, education and protection, but not directly providing services to children and families), service-provider and beneficiary levels. Policy architecture maps were developed to illustrate links in the administrative hierarchy between national, subnational and local levels of a particular sector or sectors of ECD services.

The report first presents country-level data from interviews, focus group discussions and content analyses, addressing six broad areas of the ECD systems explored: service goals and implementation, key aspects of governance, governance of finance of ECD, quality of the ECS, historical and ideological understanding of ECD, sociopolitical understandings of governance and finance, and understanding of the association between policies as guiding documents and service implementation. Subsequently, a cross-country analysis of emerging themes and key findings was conducted. First, main actors in ECD and implications for capacity building are discussed.

The study applied a set of tools to systematically identify the main players in the system providing services to young children and families, their role, and their interrelationships across both administrative levels and sectors. Our analysis highlighted the need for different forms of capacity building among these actors and variations across the three countries. Second, an analysis of horizontal and vertical coordination mechanisms is presented.

Our vertical and horizontal analysis of coordination mechanisms showed that subnationally, between national and village levels (namely, the province and district), the weakest horizontal 
coordination of government was demonstrated. In Kenya, the presence of provincial and districtlevel officers and intersectoral committees that focused on coordinated ECD services suggested the emergence of mid-level mechanisms for coordination. Third, the influence of policy on the coordination function of governance was explored. A unique set of findings was obtained in Kenya and Cambodia, regarding the role of established policies in promoting the governance function of coordination. Such policies were not found in LPDR, indicating key differences in macro-policy frameworks. Fourth, local governance structures as a key lever for ECS improvement were studied followed by the exploration of the role of beneficiaries in governance of ECS.

This initial exploratory study examines the governance and finance of ECS in three countries using an in-depth qualitative approach. The methodologies and tools provide an innovative strategy built upon the literature of governance and finance to understand how to improve access, quality and equity of ECS. Cross-country analyses reveal key emerging trends in ECD systems governance at different levels and around crucial dimensions, including actors, coordination, policy architectures, and local-level perspectives. The findings of this study have implications for strengthening systems of global ECD systems research.

\section{INTRODUCTION}

The field of early childhood development (ECD) is growing rapidly in scientific knowledge, programmatic initiatives and policy advocacy. However, these trends are not translating into improvements in the situation and outcomes for young children. A strong and growing base of evidence indicates that equal access to quality ECD can reduce the impact of risk factors and improve outcomes. Most work on improving equity, access and quality of ECD has examined it from a service level, i.e., the contexts and settings in which the programmes are delivered (Britto, Engle \& Super, 2013). However, one of the largest drivers of influence is the system that provides the infrastructural and operational support for the services. The system includes the larger organizational and institutional structures within which ECD services are situated. The governance of that system is vital to the success of its implementation in supporting services.

Governance, simply stated, lays out the roles and responsibilities for the key stakeholders and partners who are involved in the design, coordination, finance, implementation, support, and monitoring of services being implemented at scale. If well designed and supported by a culture of consultation and coordination, governance has the potential to create nationally sustainable policies and systems to guide national programming and services. In the field of early childhood, the issue of governance of policies is relatively new but vitally important.

The governance functions that are most important for early childhood services and programmes are yet to be elucidated. Because ECD requires the integration of services to achieve holistic child outcomes across survival, health, nutrition, growth, learning, development, protection and participation, the coordination function of governance is vital. Furthermore, because countries typically do not have a social sector dedicated to ECD, services for young children and their families tend to be fragmented across sectors without coherence in the delivery of coordinated services. Additionally, government budgets are allocated by different sectors and ministries. If ECD does not have a ministerial home, then understanding the governance of finance is essential to improve 
resource allocation and efficiency for ECS. Therefore, understanding governance is paramount for improving the equity, access and quality of ECS.

The broad aim of the current study was to understand the governance of Early Childhood Services (ECS) in three low-income countries, Cambodia, Kenya and Lao PDR. To that end, the study focused on the implementation and delivery of ECS, the division of administrative and fiscal responsibilities and the policy landscape within which ECS operate. This report presents the findings of a qualitative approach to the analyses of governance of ECS. In this chapter, we describe the conceptual framework that guided the research (for a fuller description of the conceptual framework, see Britto, Yoshikawa, Ponguta, Oh, \& Reyes, 2012).

\subsection{What is Early Childhood Development (ECD)?}

The term "early childhood development (ECD)" represents a multifaceted construct that refers to both the developing child and the multi-layered context that influences the child's development.

With respect to the child, developmental science of early childhood defines this age period as extending from the prenatal stage through the transition to primary school (i.e., age 8 or 9) (McCartney, \& Phillips, 2006; UNICEF, 2002a). With respect to domains of development, a holistic approach includes, but is not limited to, physical, cognitive, linguistic, socio-emotional, and ethical and spiritual development, as well as a sense of national or group identity (Britto \& Kagan, 2010; Naudeau, Kataoka, Valerio, Neuman, \& Elder, 2011).

Context is the second aspect of our definition. Socio-ecological models have illustrated the multilayered nature of contexts (Bronfenbrenner, 1979; Chawla, 2002; Hodgkin \& Newell, 2007; Robinson, Eickelkamp, Goodnow, \& Katz, 2008) with environments closest to the child - such as caring, safe and stimulating family and home environments - having the most direct impact on development (Bornstein, Britto, Nonoyama-Tarumi, Ota, Petrovic, \& Putnick, 2012). More distal factors - including relevant policies, systems, and cultural and social influences - have a more indirect influence (Irwin, Siddiqui, \& Hertzman, 2007; Shonkoff \& Phillips, 2000; Super \& Harkness, 1999). Achieving the full developmental potential of a child is influenced by the interaction between the child and the context (Richter, 2010; Rutter, 2002).

However, for a third of the world's children, the context is lacking the essential elements to promote and support development (Britto \& Ulkuer, 2012). Understanding how to enrich contexts through quality services for all is essential if we want to achieve equity in outcomes for all children. The context, as used in this paper, focuses on the services and policies associated with ECS provision.

\subsection{What is Governance of ECS?}

One of the largest influences on contexts where children grow and develop, is national and international level policies and their operationalization into systems of service delivery. Policies impact change because they address the policy and financial structures that support service provision. In order to explain how governance is employed in the current study, we first describe the levels to which they applied: policy, system, and service. 
Policies are defined with respect to the sponsorship, focus, and target of social issues. For the purpose of the current study, our definition of national policies relevant to ECD are those that are supported by publicly funded institutions (e.g., government), have an impact on the lives of young children (specifically prenatal to 6 or 8 years of age depending on the country) through policy instruments (e.g., cash, credit, subsidies), and services that meet the needs of young children and families. These policies aim to achieve national goals and targets and are often influenced by international frameworks (World Bank, 2006; Zigler \& Hall, 2000). National policies impact changes that support institutions and communities that identify and meet the survival, development, and protection rights of young children and their families by providing intervention and prevention services to children and allocating funding for services (Britto, Cerezo, \& Ogbunugafor, 2008; Vargas-Baron, 2005).

Systems are defined as the institutions, organizations and resources that work together to achieve a common set of goals through response services and programmes that treat beneficiaries fairly (WHO, 2007). Systems are guided by policies, as well as politics, ethics and values that operate through organizations and service delivery mechanisms that require human and financial resources and need to be regulated to ensure quality and standards (Roberts, Hsio, Berman, \& Reich, 2008).

Systems consist not only of the supply side or inputs, i.e., government agencies, and public and private providers, but also by the demand side or beneficiaries and the multiple stakeholders who participate in the system (World Bank, 2011). To function effectively, a system needs to have an adequate level of financial resources, trained staff and human capacity, appropriate governance and accountability mechanisms, and strong management that enables it to meet its goals. A systems level approach is an effective way to examine the influence of services at a broader level than individual programme impact. In part, the inequitable distribution of ECS can be explained by poor coordination and strengthening of the systems level (Abt Associates, 2011). 


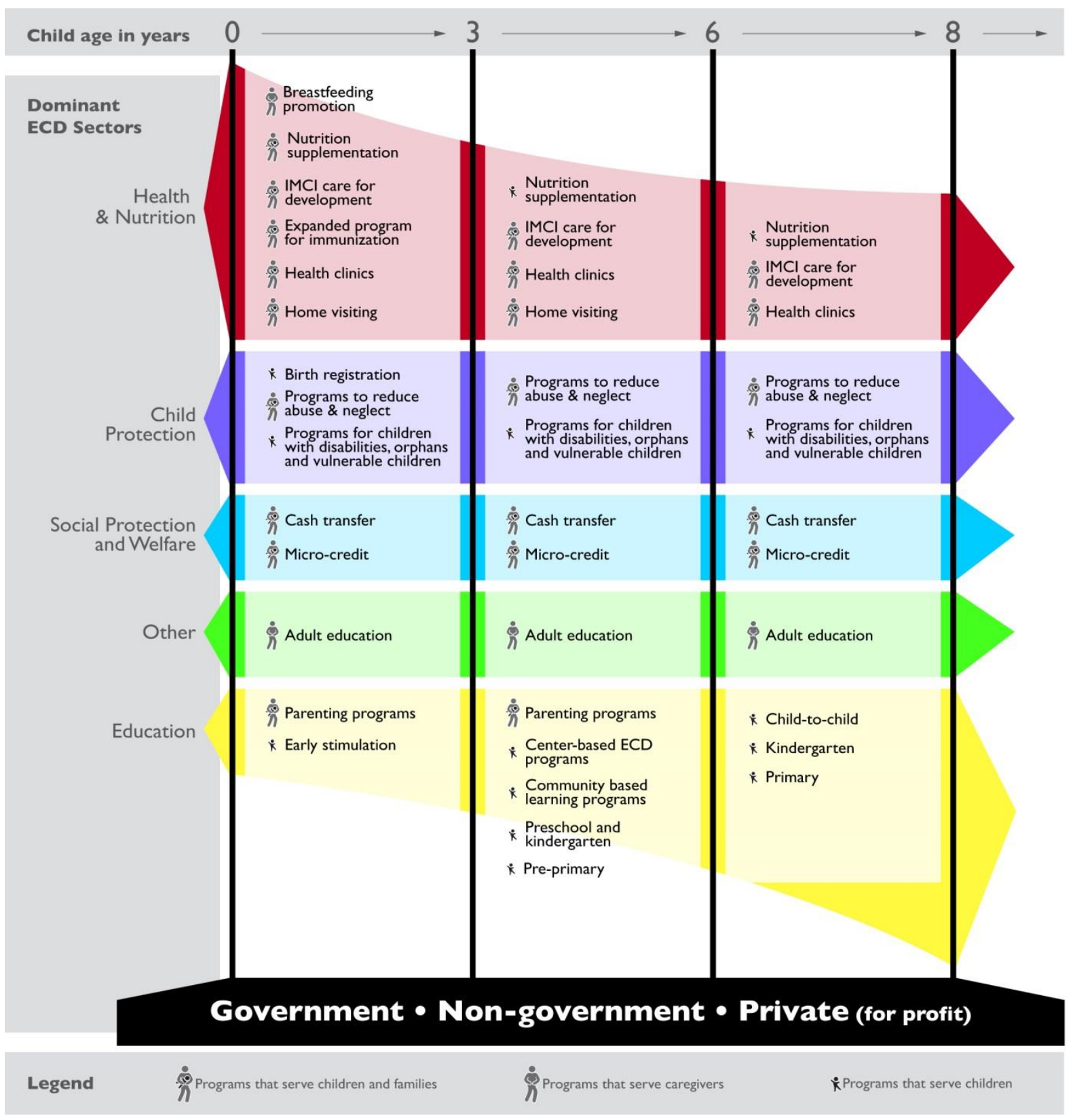

Source: Britto, Yoshikawa, \& Boller, 2011

Services - ECD is marked by a myriad of services (Figure 1). However, all services may not be available to children and families, especially those from marginalized populations. Given the emphasis of this study, it is important to understand the complexity of the range of services that fall under the rubric of Early Childhood Services (ECS). The age of the child is the first critical dimension that distinguishes ECS. In the earliest years, interventions tend to focus on health and nutrition services and systems of support within families and communities (WHO, 1999). Second, there is a range of sectors involved in ECS provision that typically include health, nutrition, sanitation, education and protection (Vargas-Baron, 2013). At the level of service delivery, the location or setting is another dimension of ECS. For example some programmes are home-based, others are centre- or clinic-based, and still others are community-based. Services are also distinguished by the generation of the beneficiary. For example, some pre-primary programmes 
are single generation, only serving the children to the exclusion of the parents (Bowman, Donovan, \& Burns, 2001). Finally, the auspices under which services are sponsored also differ by government, non-governmental agency, and private, for-profit agency. Therefore, with respect to governance and finance, an understanding of the rubric of ECS is important as it has implications for maintenance of quality, adherence to regulations, coordination and funding (Vogler, Crivello, \& Woodhead, 2008).

Governance - In this study, governance is the process of allocating responsibility of ECS within and across levels of government and between public and private sectors of society. This process of allocating responsibility is implemented directly through political processes, policies, resource allocation and service support, and indirectly through standard-setting, regulation, accountabilities and feedback mechanisms (Kaufmann, Kraay \& Mastruzzi, 2004).

The governance of early childhood development (ECD) services is situated within larger political, public policy, cultural and economic systems (Yoshikawa \& Currie, 2011), including the redistribution of financial and other resources across groups defined by class or other characteristics (UNICEF, 2008), types of social welfare states (UNESCO, 2006), degree of decentralization of government; and societal cultural norms and values concerning childhood (Dahlberg, Moss, \& Pence, 2007;Tobin, Hsueh, \& Karasawa, 2009). For example, patterns of inequitable access to ECS can be explained by rural residence (UNESCO, 2007), income poverty and inequality (UNICEF, 2012; Wilkinson \& Pickett, 2009), political histories of colonization and conflict (Pence, 2004; UNESCO, 2011) and value of ECD as expressed in greater investments and redistribution of funds (Arts \& Gelissen, 2002).

Of the range of governance functions, vertical coordination or decentralization from national to lower levels of government and horizontal coordination with respect to intersectorality are important for ECS. Decentralization is the process by which decision making and responsibilities are shared among the multiple vertical levels of government that have impacted ECS in several countries. Decentralization has also resulted in bringing new actors into ECS. For example, in China, the transition from an entirely centrally planned economy to a merged central/market economy has resulted in a surge in private early childhood programmes (Cai \& Feng, 2007). Finally, decentralization can create opportunities for new leadership in ECS because ensuring successful implementation and delivery of ECS requires collaborative efforts amongst local government officials, practitioners, community residents, and families as important stakeholders (Yoshikawa, Rosman \& Hsueh, 2002).

At the heart of quality ECS lies horizontal coordination, because holistic development often requires coordinated (and sometimes integrated) efforts and intersectoral approaches. Coordinated ECS are designed to enhance children's health, nutrition, cognitive development, and psychological well-being and include sectors of health, education, social welfare and protection, which typically reside in different ministries or departments. Different sectors tend to be associated with different types of ECD services across the first years of life (Kammerman, 2000). At the system level, horizontal coordination (between sectors of health and education) at mid-levels of government is as critical for service provision as horizontal coordination in central and local levels or government. 
In addition to coordination, implementation and the monitoring of service provision, the financing of such services requires special attention. This concerns the processes and mechanisms for funding ECS programmes, and includes the allocation of financial resources and cost estimations of such programmes. Finance pertains to what are conventionally referred to as cost, budget, and financing dimensions. Finance is particularly important for ECS for several reasons, in addition to it being a resource that all social services require. First, in developing countries, the increase in government spending on education has been limited to approximately one-percentage point of the gross domestic product (Baldacci, Clements, Gupta, \& Cui, 2008). Not only is there inadequate public funding for primary education among developing countries (Delamonica, Mehrotra, \& Vandemoortele, 2004), but also, in general, developing countries give low priority in terms of public spending to pre-primary education (less than $10 \%$ of total public education expenditures) (UNESCO, 2006). Therefore, with no substantial increase in funding in the near future, efficient finance mechanisms are required to increase the quality and effectiveness of services. Creating a fiscal space for ECS is vital and important.

Second, disentangling funding sources and the distribution of funds is a great challenge in the field. Funding for ECS comes from several sources - public, private, and civil society (Belfied, 2006; Naudeau et al., 2001). Public funding consists of money that is given from the government or large national funding sources for the provision of social and economic programmes and services, such as housing, health, rural development, or education. Often, this is also referred to as social spending (Sachs, 2004). This funding is meager and often generated from state and municipal taxes, as in Brazil (Schady, 2005). Private funding consists of money and contributions from individuals, households, and community members and is a growing sector in ECS (Woodhead et al., 2009). The largest funding source for ECS is civil society funding from large NGOs and donors, both national and international, with a motive to assist the social and economic development of countries (Gertsch, 2009). However, these funding sources do not follow a particular formula of coherence. Furthermore, they are often combined, which makes estimating the proportion of funds difficult. Funds for ECS are also difficult to track, as some funds get allocated directly to families, e.g., access to credit to families to increase the take-up of health and education services (Barnes, Gaile, \& Kimbombo, 2001; Barnes, Keigh, \& Nemarundwe, 2001; Pronyk et al., 2006) or conditional cash transfers to improve the participation rates in education (Levy, 2006). Funds are also allocated directly to programmes through block grants and grants-in-aid (Kaul \& Sankar, 2009). Therefore, the combination of multiple sources of funding and multiple mechanisms for distribution is important to understand if finance efficiency for ECS is to be improved.

The governance of finance is an important area of inquiry because the effectiveness of obtaining funds and disbursing funds relies on the quality of governance of the mechanism mediating it. The transfer of funds from the source to the recipient is guided by agencies and/or individuals who execute a series of roles and have responsibilities linked to this transfer. As a result, the effectiveness of even the most sustainable and large sources of funding can be mired by poor governance (Burnside \& Dollar, 2000; Rajkumar \& Swaroop, 2008). On the other hand, governance is effective only to the extent that there are mechanisms by which funds are specifically allocated to ECS programmes. Otherwise, government programmes and policies cannot be fulfilled. 
Governance is often understood with respect to its ability to impact access, equity and quality of services. The concept that is most clearly defined is access, which is understood with respect to the provision of programmes and services, for "all", regardless of social groups, geographical areas or any social, economic and cultural population categorization. Access (or level of coverage) refers to the level of provision of service and is measured as the percentage of children who participate in ECS (Olmsted, 2002). Arriving at a universal definition of equity and quality of ECS is more complex. As a normative concept, equity has a long history in religious, cultural and philosophical traditions (World Bank, 2005) and is concerned with equality, fairness and social justice, topics that are also the subject of debate (Jones, 2009). Equity for the purposes of this study is understood as the elimination of disparity and assurance that the greatest possible opportunity is available for "all". Quality has been identified as the critical ingredient in service provision that is linked with improved child health, development and well-being. Quality is the extent to which structural and interactional aspects of services appear to promote holistic development, growth, and learning, with the understanding that quality is contextually and culturally driven. To the degree possible, the association between governance equity, access and quality was examined in the current study.

We close this section by highlighting an additional feature of our conceptual framework. The demand side of ECS has been explored fairly minimally in studies of governance. This field has been generally driven by a supply-side model. However, the recent rise in several aspects of ECS, such as the burgeoning growth of the private sector, indicates that the demand side for services warrants further inquiry (Woodhead \& Strueli, 2013). Incentivizing participation in ECS is a complex issue. Because in the early childhood period children do not enroll themselves in programmes or services, parents and their preferences are clearly an important driver of the effects of governance ultimately on children's outcomes. It does not refer only to seeking of ECS or take up of ECS, but also communicating to parents the value and importance of these services. Work in this area is limited, but is however necessary to correct the imbalance in understanding governance of ECS. In our study, through focus groups in each local context in each of our 3 countries, we gathered data directly not only from beneficiaries (families using particular ECD services), but also from families who were not using services. Thus, a portion of our study shed light on issues of the supply side of ECS (see e.g., Section 4.5).

\subsection{Research Questions}

Given the review of the literature and lack of consistent findings, the following questions were addressed in the study:

1. What are some key policy documents that determine the ECD policy architecture, ECS provision and governance structures in the country?

2. What are the coordination mechanisms between sectors of government for the governance functions of planning and development, implementation and delivery, monitoring, finance, inspection and supervision for ECD services?

3. What are the coordination mechanisms between the main actors, government, nongovernment and private (for profit) for the governance functions of planning and development, implementation and delivery, monitoring, finance, inspection and supervision for ECD services? 
4. What are the coordination mechanisms between national and sub-national level structures of the system for the governance functions of planning and development, implementation and delivery, monitoring, finance, inspection and supervision for ECD services?

\section{STUDY METHODOLOGY}

A multi-phase multi-country study was conducted to explore the study questions. The conceptualization of the study was drawn from an extensive review of the literature on the governance and finance of national health and education systems in low- and middle-income countries. The study relied primarily on qualitative methods of content analyses of national documents and policies, semi-structured interviews and focus group discussions with key informants and observations of services. In this chapter we describe the sampling framework, the study design, and the instrumentation.

\subsection{Sampling Framework}

The sampling for the study considered three sets of criteria: (i) geographic sampling of countries and, within country, regions or provinces; (ii) policies, sectors, systems and services to be analyzed; and (iii) sampling of respondents.

\section{1.a. Geographic Sample}

Two levels of geographic sampling were conducted. At the first level, regions were selected from a global sample based on consultation with study partners (UNICEF Innocenti Research Centre and UNICEF). The two regions selected were the East Asia and Pacific, and East and South Africa regions, as they account for a majority of the young child population, globally. For country selection within each region, the following criteria were used: a combination of country indicators of ECD; interest in the study; and ability to support the implementation of the study in similar countries within a region. Based on these criteria, Cambodia and Laos PDR were selected for EAPRO and Kenya for ESARO. ${ }^{1}$

The next level of sampling was at subnational levels, to select regions of the country that allowed for the exploration of the range of services for young children with families within countries. Therefore, in each country three regions were sampled from the most advantaged (in each of these countries, this was represented by the capital), median and least advantaged with respect to child well-being and ECS access indicators. Median and least advantaged were typically operationalized as rural and remote areas of the country, respectively. The sampling continued to the lowest (local) level of government where the services were delivered to the families, e.g., village, community or commune. In each country, these levels varied slightly and had different names. For example, in Lao PDR the levels of government are central, provincial, district and village. Figure 2 illustrates the sampling frame as applied broadly to the 3 countries and in detail for Cambodia. It should be noted that there was some variability in the application of the selection

\footnotetext{
${ }^{1}$ Zambia was also selected from ESARO. However, due a series of reasons linked with coordination and management, the study was implemented only in Kenya by the time this report was completed. Currently, the process is underway to conduct the study in Uganda.
} 
criteria of regions, districts, provinces, and villages because decisions were made taking into consideration available data on child well-being and access to services and consultation with local experts and the study focal point. Another key consideration in sampling was the feasibility to travel to the location to conduct interviews and observations.

Figure 2. Sampling Frame: Global to Local Levels of Geographic Sampling

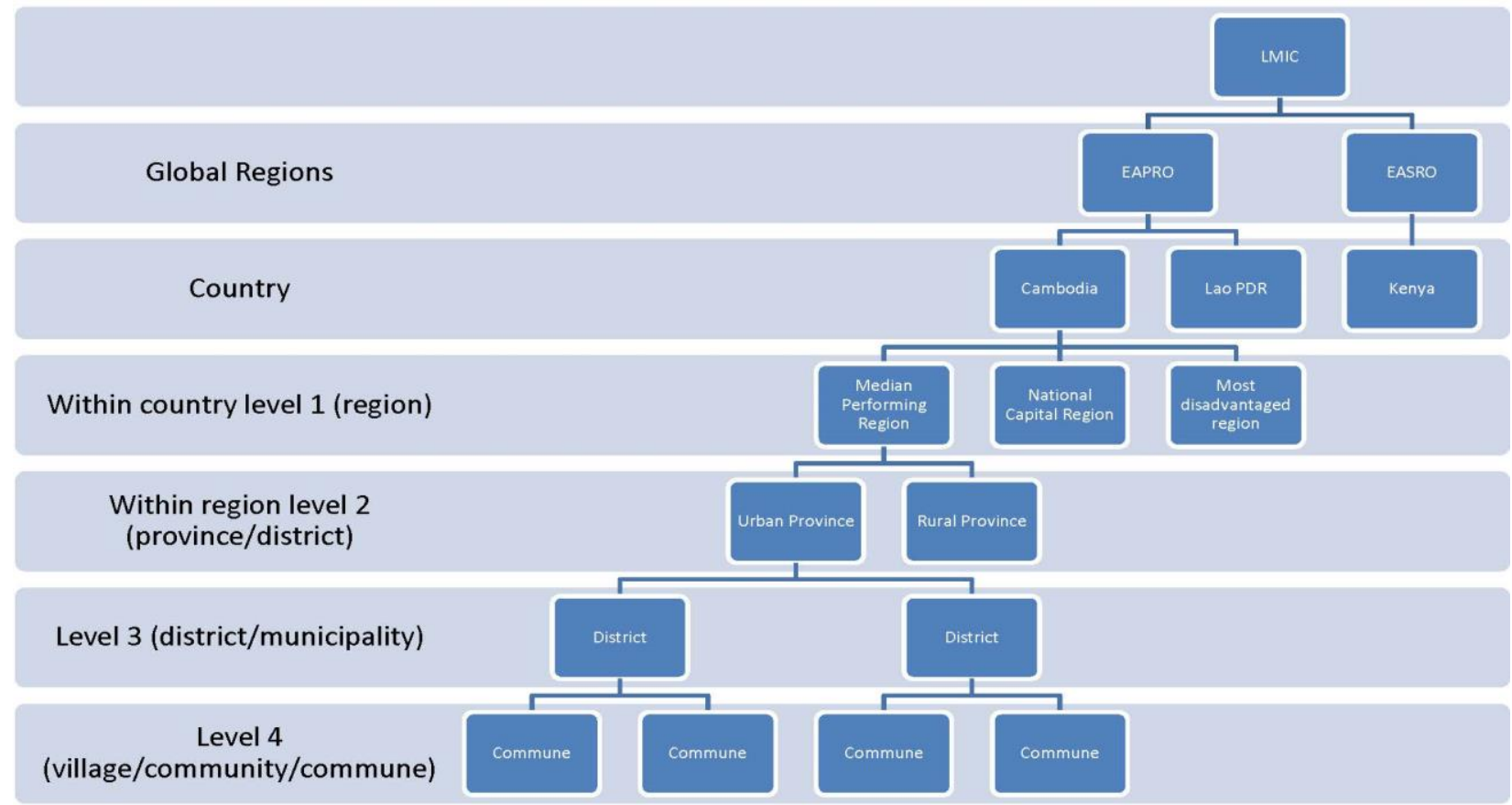

\section{1.b. Sector and Service Sample}

The next level of sampling was undertaken to identify the candidate services that would enable an investigation of ECS governance, quality, access and equity. In most countries there is no ECD sector per se; therefore, selection of the sectors and services had to be undertaken.

This sampling first relied on overviews of the national policies, statements, strategies, laws and guidelines that influence ECD in the country. Four categories of national documents have been associated with ECD governance: ECD policies; social policies; legislation and laws; and national development policies (Britto, Ulkuer, Hodges \& McCarthy, 2013). Using this framework, through online searches and email solicitations for each country, a set of key policies were collected. These policies covered the main sectors of health, education and protection, and also included national poverty reduction plans, local governance policies, etc. The final set of policies included in the study depended on online accessibility, respondents' identification of key documents and availability of documents in English.

The next level of sampling consisted of the identification of services. The following inclusion criteria were developed to identify candidate services for inclusion in the study: the service should directly address children in the ECD age bracket as defined by the country (e.g. birth to 6 years of age); it should be implemented at sufficient scale to enable an examination of access (typically across at least several regions or provinces); it should be feasible to observe the programme; and 
permission to interview service providers and system level staff associated with the programme should be granted. The services could be sponsored by government and/or non-governmental agencies (due to the close coordination between large-scale publicly and NGO-funded services, we did not restrict ourselves to solely government-funded services). We did not include services that were individual pilots or demonstration efforts occurring in single provinces, as they would not enable a study of governance from a sufficiently broad systems perspective.

\section{1.c. Respondent Sample}

There are three levels of respondents for the study: system-level actors; service-level actors; and beneficiary families and children. These respondents cut across government and non-government agencies/bodies.

- System level informant: These individuals are part of the system that supports the provision of the service, for example, the manager of social development at the regional level. They work in the sectors of health, education and protection, but do not directly provide services to children and families. They are working at national, regional, provincial, and municipal levels.

- Service level informant: These individuals directly provide services to children and families, e.g., teachers, nurses, midwives. They interact with the families and children.

- Beneficiaries: These are the families and children who receive the services.

\subsection{Instrumentation}

Three sets of tools were developed for this study: policy architecture maps; semi-structured interviews; and focus group discussion protocols.

\section{2.a. Policy Architecture Maps}

We define policy architecture as the governance structures specified in national documents that pertain to early childhood. Three main components of the policy architecture are: (i) the main policy or national documents that guide the provision of ECS in the country; (ii) the main actors or stakeholders who support, coordinate, plan, implement and provide services to young children and families, including the organizations and the entities (units, departments, directorates) within them that are involved in ECD, including links between the national, subnational, and local levels; and (iii) the relationship between the policy documents and the actors in ECS and the way provisions are structured (both internally and in their external relations).

The process of charting the policy architecture entailed: (1) a review of the national policy documents of the country linked to ECD to extract the main provisions, actors and services; (2) an analysis of the semi-structured interview data on the governance of ECS at national, subnational and local levels; and (3) a mapping of the relationships between the documents and service provision. In Chapter 3 we present the policy architecture maps from the three countries.

The policy architecture maps we developed typically showed intended links in the administrative hierarchy between the national, subnational and local levels of a particular sector or sectors of ECD services. By then interrogating each of these links through key informant interviews at each administrative level, we aimed to detect the presence of functional coordination and/or 
bottlenecks both vertically (across levels) and horizontally (across sectors; across provinces or geographic regions).

\section{2.b. Semi-Structured Interview and Focus Group Discussion Protocol}

The system- and service-level respondents were administered semi-structured interviews. Focus group discussions were conducted with families with young children to understand beneficiary perspectives and demand side of services. On average, the interview and the Focus Group Discussion (FGD) took 60 to 90 minutes. These tools were developed based on an extensive review of the governance and finance literature of ECS in LMIC (Britto, Yoshikawa, Ponguta, Oh, \& Reyes, 2012).

Both tools addressed the following areas or topics:

1. Service goals and implementation: the focus of this section was on understanding the design of the service and how it is being implemented.

2. Aspects of governance: planning, coordination, decision making, accountability, supervision, design, and monitoring and evaluation;

3. Governance of finance of ECD: generation of funds, decisions around allocation and distribution of resources and costs and expenditure of programmes;

4. Quality of the ECS: training and certification of service providers, curricula, infrastructure, materials, service provider and beneficiary interactions and relationships;

5. Historical and ideological understanding of ECD and sociopolitical understandings of governance and finance; and

6. Understanding of the association between policies as guiding documents and service implementation.

The main topics were adapted slightly to the country depending on the context, provision of services and respondent. Furthermore, depending on the respondent, not all questions could be asked because of their designation or agency affiliation.

\subsection{Procedure}

In each of the three countries, the study was conducted in three phases.

\section{3.a. Phase I: ECD Situation Analysis}

The first phase was an ECD situation analysis with the following goals: (i) to create a country profile of ECD outcome and access indicators taking into account the political, economic, social and cultural contexts; (ii) identify the specific policies, systems and services to be studied; (iii) identify the regions, provinces and municipalities to be studied; and (iv) determine the agenda for the country visit to occur in Phase 2.

\section{3.b. Phase II: In Country Visit}

The purpose of phase 2 was to conduct an in-depth case study of ECS in the country. The visits, all conducted in 2010, were the result of highly collaborative planning between the study team and local partners, including UNICEF and NGOs. The study visits lasted about two weeks in duration (See Table 1 below for an overview) and covered the interviews, FGDs and observations. 


\begin{tabular}{|c|c|c|c|}
\hline & Cambodia & Lao PDR & Kenya \\
\hline Areas Visited & $\begin{array}{l}\text {-Province 1: Kampong Thom } \\
\text {-District: Kampong Svay } \\
\text { district } \\
\text {-Villages: Snor village and } \\
\text { Traping Reusei village, both } \\
\text { in Trapaing Reusei commune } \\
\\
\text {-Province 2: Oddar } \\
\text { Meanchey } \\
\text {-District: Chong Kal district } \\
\text {-Villages: Kouk Pongro } \\
\text { village, Cheung Tieng village, } \\
\text { and Sre Prang village, all in } \\
\text { Cheung Tien commune }\end{array}$ & $\begin{array}{l}\text {-Province 1: Vientiane } \\
\text {-District 1: Xaysomboun } \\
\text {-Villages: Hinhouaseaua; } \\
\text { Muang Soum; Nam Thea } \\
\text {-Province 2: Xienghouang } \\
\text {-District 2: Pek } \\
\text {-District 3: Mok } \\
\text {-Villages: Thachock, Na } \\
\text { Theur }\end{array}$ & $\begin{array}{l}\text { - Province 1: North } \\
\text { Eastern } \\
\text { - District: Garissa } \\
\text { (provincial capital) } \\
\text { - City/town: Garissa } \\
\\
\text { - Province 2: Eastern } \\
\text { - District: Machakos } \\
\text { - City/town: Machakos }\end{array}$ \\
\hline $\begin{array}{l}\text { Semi- } \\
\text { structured } \\
\text { Interviews and } \\
\text { Focus Group } \\
\text { Discussion }\end{array}$ & $\begin{array}{l}\text { National Level: } N=18 \\
\text { Provincial Level: } N=11 \\
\text { Village Level: } 4 \text { focus groups } \\
\text { per village (total } N=16 \text { focus } \\
\text { groups) }\end{array}$ & $\begin{array}{l}\text { National Level: } N=18 \\
\text { Provincial Level: } N=7 \\
\text { District Level: } N=5 \\
\text { Village Level Systems FGD: } \\
N=10 \\
\text { Village Level Beneficiary } \\
\text { FGD: } N=6\end{array}$ & $\begin{array}{l}\text { National Level: } N=14 \\
\text { Provincial Level: } N=4 \\
\text { District Level: } N=8 \text { and } 1 \\
\text { FDG, } N=6, \\
\text { NGOs: } N=1 \\
\text { Service Level: } N=8 \\
\text { Beneficiary Level: } 1 \text { FDG, } \\
N=12\end{array}$ \\
\hline $\begin{array}{l}\text { Systems and } \\
\text { Services } \\
\text { Studied }\end{array}$ & $\begin{array}{l}\text { Education: community } \\
\text { preschool program } \\
\text { Home-based Preschool } \\
\text { program } \\
\text { State preschool program } \\
\text { Health: C-IMCl }\end{array}$ & $\begin{array}{l}\text { Health: Expanded } \\
\text { Immunization Program } \\
\text { Education: public preschool } \\
\text { and primary school }\end{array}$ & $\begin{array}{l}\text { Health: Essential Health } \\
\text { Package, C-IMCl, EmOC } \\
\text { Education: public } \\
\text { preschools } \\
\text { Protection: children's } \\
\text { home }\end{array}$ \\
\hline
\end{tabular}

\section{3.c. Phase III: Data Analysis and Reporting}

The final phase of the study included analyses of the interview and focus group data, and content analyses of the national policies and laws to extract trends and patterns in results. This process was conducted independently by each country study team and results were shared across study teams to extract overarching themes. We looked for points of congruence and divergence across multiple data sources and identified emergent themes (e.g., field notes and analytic memos, document review vs. field observation or interviews with local vs. central-level informants). Then, the analyses were shared across the three country teams - Cambodia, Lao PDR and Kenya - to draw comparisons and highlight unique characteristics of ECD systems in respective contexts. As the analysis proceeded, draft policy architecture maps were drawn and revised iteratively. 


\section{STUDY FINDINGS BY COUNTRY}

In this chapter we present the highlights from each of the 3 country studies on the key issues of governance of ECS. Each country case study is presented by an ECD and Governance Situation analysis followed by key country-specific themes and patterns. In the next sections, the individual country findings are combined to present a set of emerging themes and ensuing recommendations.

\subsection{Cambodia}

Cambodia is a developing country in South East Asia, emerging from decades of civil conflict. It has made substantial progress in designing policy and building governance systems to provide comprehensive early childhood development (ECD) services to some of its youngest children; however, many challenges remain and access remains a major problem. Cambodia remains one of the poorest countries in Asia. The 2009 Human Development Report by the United Nations Development Programme (UNDP) ranks Cambodia 137th out of 180 UN member states on its Human Development Index (HDI). Additionally, the population of Cambodia is one of the youngest in the world, largely due to the genocide under the Khmer Rouge; $41 \%$ of the country's population is under age 18. Though the traditional core family structure in Cambodia revolves around extended families, the communities and villages, once composed of extended kinship networks established for generations, have been increasingly fragmented by political violence, natural disasters, and forced displacement. Consequently, families with young children are confronted with growing demands and challenges of child-rearing and parenting that are often greater than they can meet.

\section{1.a. ECD and Governance Situation}

The ECD situation in Cambodia is one that needs immediate attention. As presented in the table below, on several indicators of child health, education, development and well-being Cambodia ranks poorly.

\section{Table 2. Early Childhood Indicators}

\begin{tabular}{|l|l|}
\hline Indicators & \\
\hline Population (millions) & 13.4 \\
\hline Population under 5 & 1.4 \\
\hline Number of births ('000) & 174 \\
\hline Under-5 mortality rate & 90 \\
\hline Infant mortality rate (under 1) & 69 \\
\hline Maternal mortality (per 100,000) & 461 \\
\hline Skilled attendant births & $52 \%$ \\
\hline Malnutrition (moderate \& severe) & $45 \% *$ \\
\hline Enrolment in ECE (3 - 5 years of age (2009-2011) & $19 \%$ \\
\hline \hline Source: Cambodia Census 2008 and UNICEF (2008); *National Council for Nutrition, 2002 & \\
\hline+ MoEYS, 2010 http://www.unicef.org/infobycountry/cambodia_statistics.html
\end{tabular}


Recent impact data comparing the 3 major preschool programmes in the nation (State preschool; Community-Based Preschool and the Home-Based program ) suggest that positive benefits for children's pre-academic skills are strongest for children who are in programmes with greater training and capacity building emphasis for teachers compared to other models with limited training emphasis (Rao et al., 2011). These data indicate the need for sustainable capacity building to address ECD challenges related to access, equity and quality. Therefore, our team set out to examine the system-level factors of supply and demand, as well as institutional characteristics that may facilitate or hinder the process of achieving access, equity and quality in ECS in Cambodia, across preschool education and the $\mathrm{C}-\mathrm{IMCl}$ model of health promotion as it is implemented in the country.

With respect to governance, the primary reform undertaken over the last decade has been the decentralization of the government through the creation of locally elected Commune Councils, aimed at creating a mechanism for local governance. Commune Councils, first elected in 2002, are made up of local council members who are responsible for conceptualizing development plans for the community and then making a budget proposal to the central government, based on an overall budget provided by the Ministry of the Interior directly to the commune. Many Cambodians perceive their presence in a positive light - in particular, viewing the Commune Council's role in building roads and improving infrastructure positively (Asia Foundation, 2005).

With respect to finance for services, the role of external aid and foreign donors has been integral in initiating capacity building and assisting in development management. Since its first General Election in 1993, 35 official donors and hundreds of civil society organizations have provided development aid to Cambodia in various sectors and development areas (Chanboreth \& Hach, 2008). In order to finance its budget, the Royal Government of Cambodia relies on a mix of tax levying and foreign aid, in the form of conditional grants, donations, and loans. In recent years, it has been estimated that as much as half of Cambodia's budget revenue came from international aid (General Accounting Office, 2002). In 2000, the Cambodia Development Resource Institute (CDRI) described the role of foreign aid in Cambodia, highlighting issues in the long-term sustainability of technical assistance from foreign aid and cooperation with the Cambodian government (Godfrey et al., 2002). In the area of ECS international NGOs currently greatly outspend the Cambodian government. Being so heavily reliant on foreign aid to finance its operations and services, particularly its main sector destinations (government and administration, health, transportation, education, and rural development), including ECD services, leaves Cambodia vulnerable to international economic crises.

The chief governance actors in ECD in Cambodia include government departments at national, provincial, district and local commune levels; NGO's; and international donors. At the crossministry level, the National ECCD Task Force, an Interministerial committee of NGOs and 11 ministries, is led by the Ministry of Education, Youth and Sports. Of the 11 ministries, the key players are the Ministry of Education (MoE), Youth and Sports (MoEYS), Ministry of Health (MoH), Ministry of Women Affairs (MoWA), and Ministry of Interior (Mol). Within MoEYS, three departments with chief governance and finance responsibility for early childhood education are: ECE; Finance; and Planning. At the Provincial and District levels, these offices represent the intermediate level of governance in Cambodia between the Ministries and local governance: Provincial Offices of Education; District Offices of Education; Provincial Health Departments; and 
Provincial Offices of Women's Affairs. At the local commune level, within each local commune council, responsibility for early childhood programmes rests with the Commune Committee for Women and Children (CCWC), which is made up of the Commune Chief, the CCWC Focal Point for Women and Children, Commune Clerk, Health Center Representative, and School Representative. As the fulcrum for the decentralization and deconcentration effort at the local level, the Commune Councils, established in the first local elections in 2002, are the primary mechanism for local governance and consequently, delivery of ECS.

Maternal and child health related ECS services, with primary foci on health and nutrition are supported by the $\mathrm{MoH}$ through the provincial health departments and delivered through health centres (See Figure 3). The health centres provide a range of on-site health services including antenatal care, and health workers work in villages to education families regarding maternal and child nutrition and health, immunization, and C-IMCl (Community-Integrated Management of Childhood Illness).

The policy architecture for health services in Cambodia demonstrates a strong vertical flow of decision making, planning and funding. The Ministry of Health, through the national centre for health promotion, is the principal actor in the governance and finance of this programme. This map also demonstrates that the health sector in Cambodia has a pyramidal architecture, with limited devolution of governance of finance.

A central weakness from the governance standpoint is that health volunteers and workers, in the absence of strong accountability from provincial levels, are not accountable to local commune councils. Although there is a health representative on every commune council, there is often no budget that the council allocates from its funds to support health. The semi-structured interview data indicated that plans were being developed for commune councils to contract health workers and spend some of their funds on health services for families and children. However, at the time of the study there was notable lack of representation of health in the budgeting of the councils.

Monitoring systems are not tightly aligned across vertical levels of governance in maternal and child health. For example, the links between the three vertical levels of provincial health departments, health operational districts, and local health centres were not carried through in terms of pre- or in-service training models. Typically, provincial health department staff directly train top-level staff at health centres. In turn, health centres, understaffed and serving a high degree of need among their villages, often do not have the resources or time to provide adequate training to health workers.

At the province level, there is usually no coordination of maternal and child health with other early childhood services across departments of education and health. This results in disconnects in practice, as observed in some villages where health workers were conducting maternal and child health education to entirely different subsets of village families than were enrolled in either the community-based or home-based preschool programmes. 


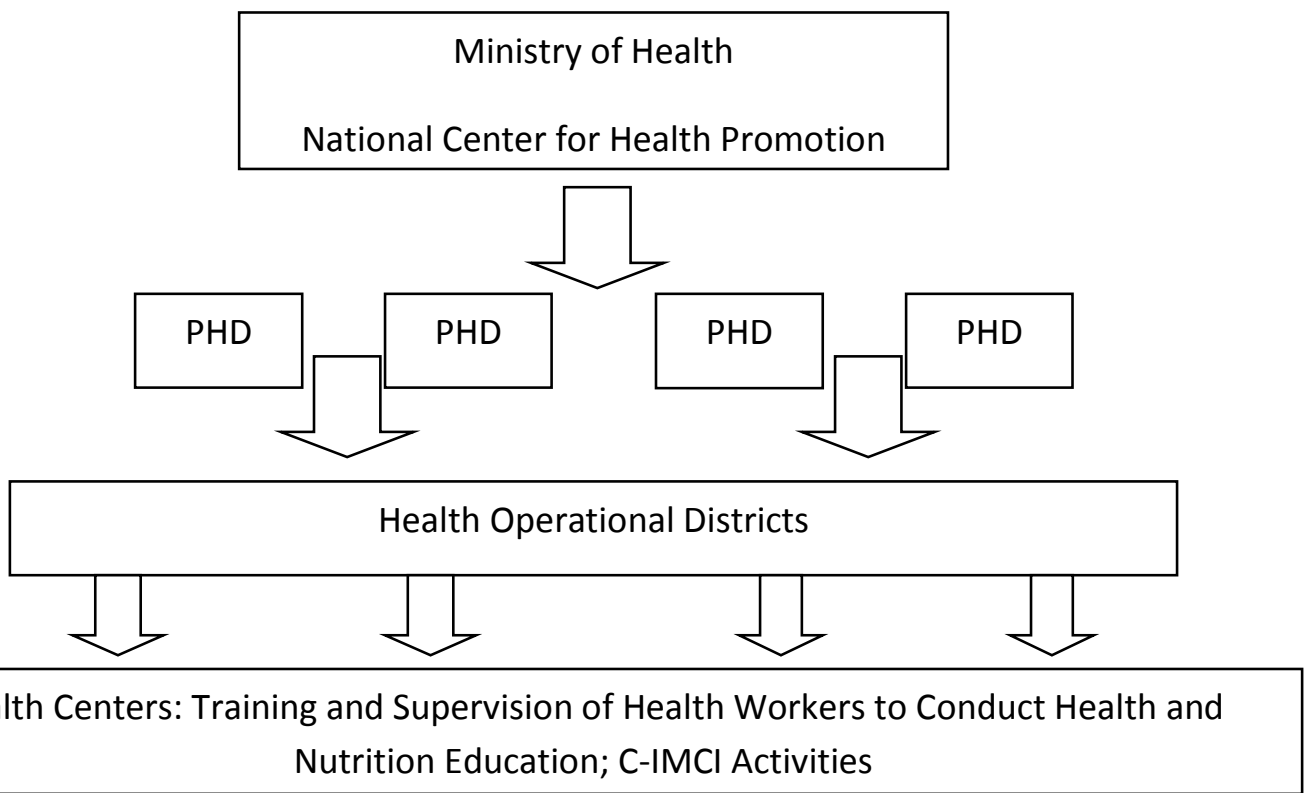

Early Childhood Education services are implemented through three key early childhood education (ECE) models: State Preschool, Community-Based Preschool and the Home-Based Program. The first model is State Preschools that provide a three-hour programme, five days a week during the 38-week school year. Teachers are government employees with two years of training at the national teacher training institute (there is only one, located in Phnom Penh). State Preschools (SPS) are funded by the Cambodian government and almost all of these preschools are attached to local primary schools in urban areas.

The second model is Community Preschools (CPS), specifically designed to provide ECE services for children 3-5 years of age who cannot access state preschools. The Community Preschools, often in rural areas, operated in spaces under the elevated houses of the teacher, provides a two-hour programme, five days a week, for 24 to 36 weeks a year. The Community Preschool teachers are selected by the local commune council and are technically supported by the POE and POWA and monitored by the CWCFP. The MoEYS provides CPS teacher manuals and the curriculum and the Community Preschool teachers receive 8-10 days of pre-service training and in-service training for 5-8 days per year. At the time of the study, many CPS teachers were volunteers; if they worked in UNICEF-supported provinces, they received 30,000 riel per month (a nominal stipend). Additionally, UNICEF supported the Ministry of Women's Affairs (MoWA) and MoEYS to train CPS teachers and CWCFP to provide parenting education programmes (MoWA \& MoEYS, 2007). UNICEF also provided materials for the programme. The commune council's Women and Children Focal Point (CWCFP) monitored the CPS regularly, using a checklist. 
Figure 4. Policy Architecture for Community-Based Preschools
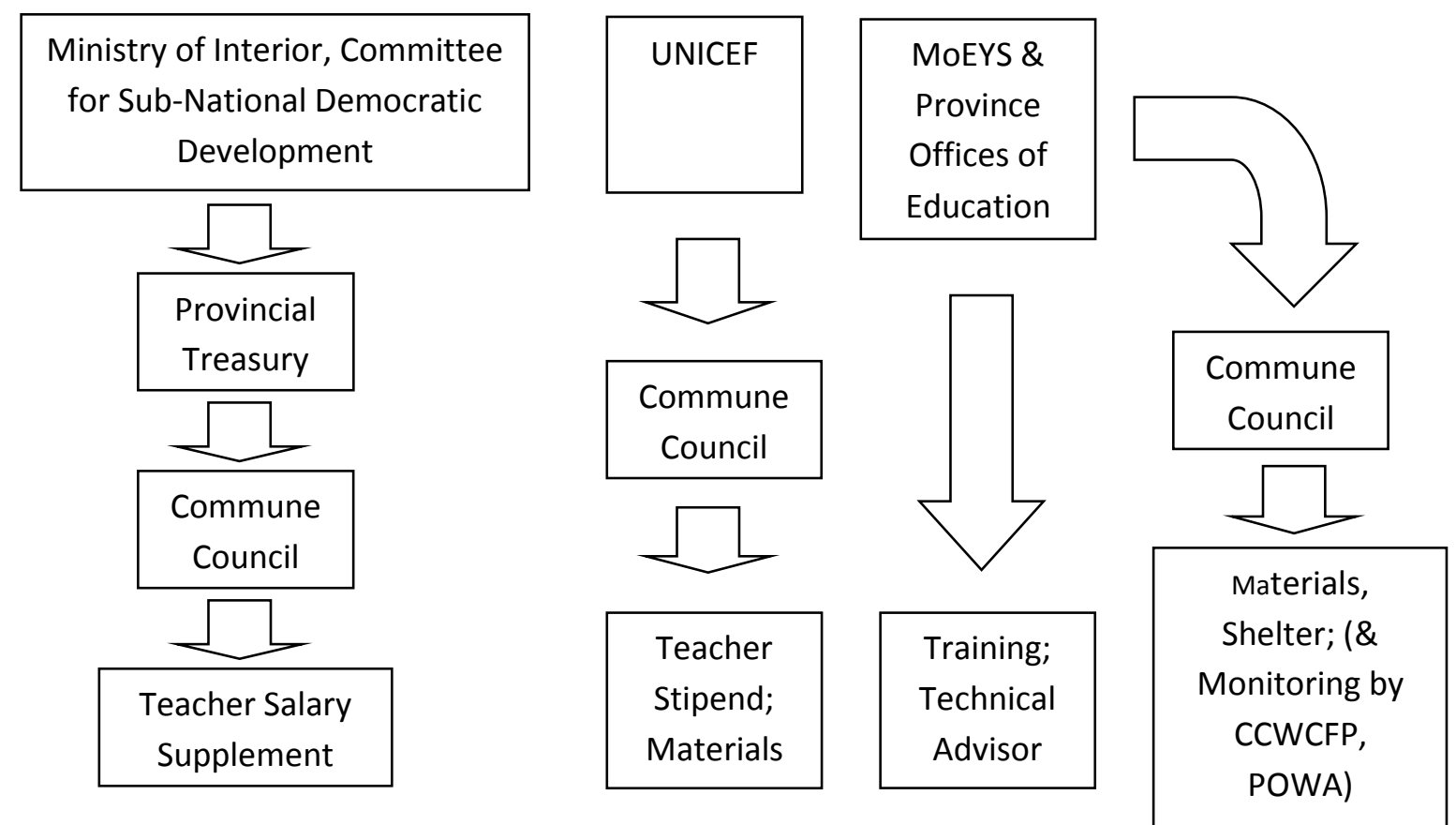

The third model is the Home-Based Program (HBP), initially developed by Save the Children Norway (SCN) and now being scaled up across the country. A relatively low-cost and flexible, culturally tailored programme, UNICEF, World Bank Fast Track Initiative and SCN were funding HBP in select provinces across Cambodia. Unlike CPS, HBP provides services for children from birth to 5 (UNICEF Cambodia, 2010d). Mothers and village volunteers form mothers' groups who then voluntarily lead the home-based programmes in the absence of formal, paid teachers. These mothers' groups are facilitated by a core mother who receives two days of training on using HBP materials to support nutrition, child well-being, and developmental stages. These groups typically meet on a monthly basis. Core mothers can also oversee multiple groups, each led by a MTL (Mother Team Leader). The core mother meets every month with the MTLs to provide guidelines, share new information, and discuss issues related to developmental milestones shown on the ECD calendar (MoEYS, undated). The model typically brings the village together around children once a month - these often turn into large supportive meetings. Social networks and friendships and mutual support are developed - the model is thus strong in social inclusion. Mothers reported not only learning important health and stimulation behaviours, but that they also transmitted these messages to their network members - e.g., to boil water. 
Figure 5. Policy Architecture of Home-based Programmes
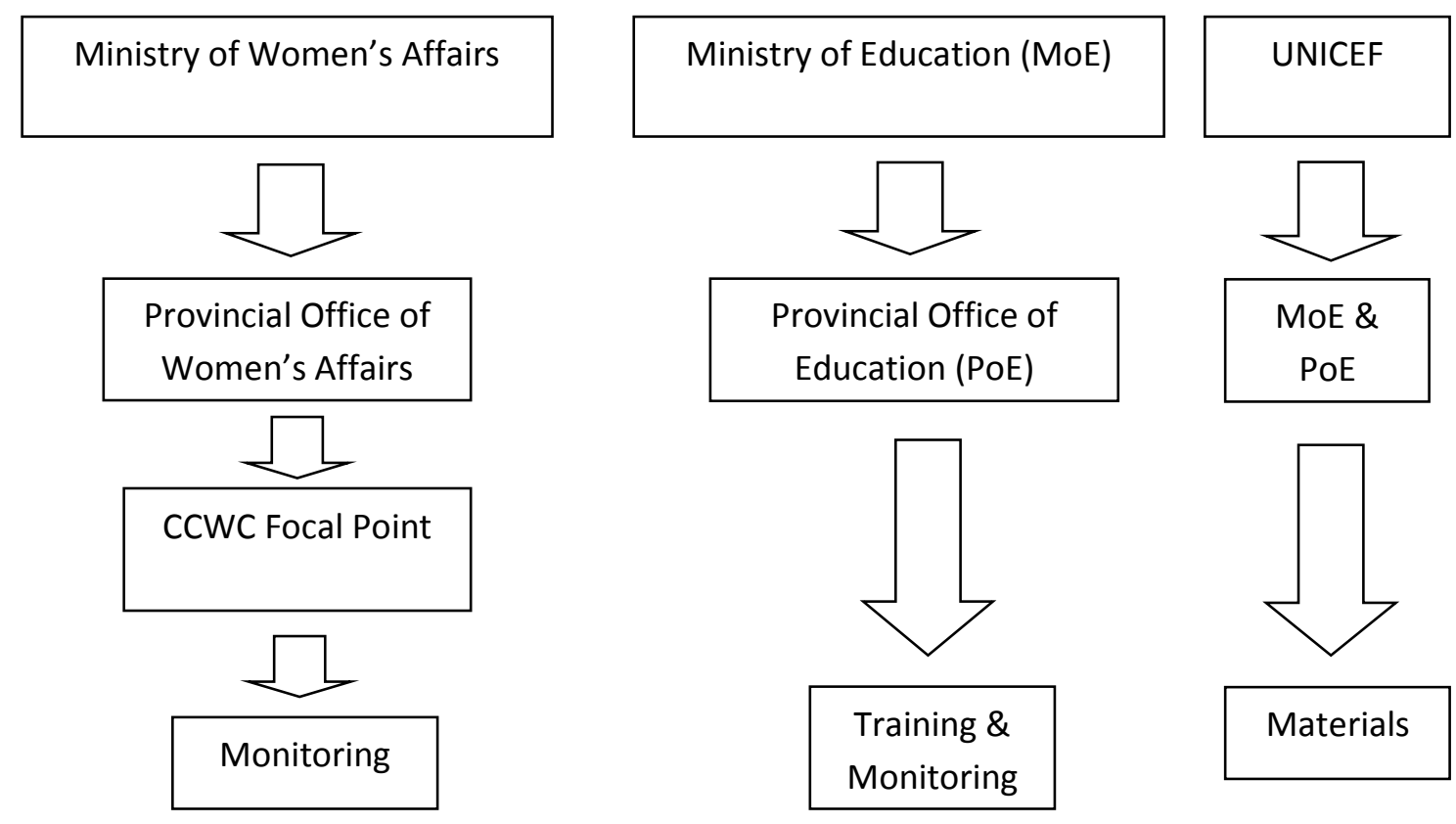

Summary of governance issues. There are many challenges with respect to governance within and across the three preschool approaches. The large disparity in training between the State Preschools, in particular (with 2 years of training) and the Home-Based Program (with 2 days of training) is reflective of larger disparities in resources, supervision, and facilities. State preschool enrolment is extremely limited due to the necessity of a basis in a public school with at least one classroom set aside for preschool. The distance of the single national training institute from the provinces constitutes another problem that partly explains low levels of access. The CommunityBased Preschools were integrated into local governance through representation on the budget of the Commune Councils. Thus among the three systems, the Community-Based Preschools included to the greatest degree links between the national and local levels of governance. However, in the villages we visited there was a relative lack of attention to issues of access for some populations - e.g., children with disabilities, who were viewed by some parents as not being "ready" for preschool education; lack of funding for a snack during the preschool session; and in terms of the hours of the preschool, relative to the work hours of parents.

The Home-Based Program incorporated cultural tailoring into its theory of change and local implementation, a real strength. However, very low levels of resources, supervision and support meant that it was not integrated well into local governance and budgeting processes.

In both the Community-Based and Home-Based Programs, the monitoring checklists were rudimentary and lacking in particular in items representing a presence of stimulating materials, organization of the learning space, and educational process quality.

Across all three models' vertical governance structure, the provincial level was weakest, relative to the national and local levels. Cross-sectoral linkages, which we examined most intensively between health and education, were largely absent at the provincial level (a pattern we also 
observed in our other country studies). This meant that local-level coordination was also weak, in that the supervision and professional development models based at the provincial level were entirely separate across health and education. The result was an observed lack of coordination between preschool teachers or home-based caregivers and health workers at the village level.

Turning to health, despite the newly implemented national guidelines through the National Nutrition Strategy, the National Policy on Infant and Young Child Feeding, and the C-IMCI programme, the system to support maternal and child health and nutrition faces severe challenges. Training and support for health workers remains weak; their integration with other early childhood serves is variable. Monitoring systems are not adequate or tightly aligned across vertical levels of governance in maternal and child health. A central weakness from the governance standpoint is that health volunteers and workers, in the absence of strong accountability from provincial levels, are not accountable to local commune councils, which has ramifications for the quality of services. Families that are distant from health centres often cannot afford the time and expense of travel to the centres, thus compromising access.

Finally, turning to the governance of finance, the predominance of NGO funding and planning was accompanied in our study by a lack of capacity for multi-year budgeting and planning at the ministerial level. The recent National Action Plan for Early Childhood, developed across 11 ministries, aims to build capacity for such budgeting. However, at current rates of investment early childhood services spending is far below optimal levels (with early childhood education spending below 1 per cent, e.g., of the education budget for the nation). Guidelines for local budget planning of the Commune Councils in the social area were being disseminated for the first time during our study. These represent a valuable first step in the prioritizing of ECD services in social spending, and in overall adequate representation of social spending relative to infrastructure investments at the local level.

Thus, although substantial progress has been made in governance, finance and implementation of ECD services in areas of health and education in Cambodia, the links between national, provincial and local levels, coordination across sectors (particularly at the provincial and local levels), and overall levels of investment and planning, remain relatively weak.

\subsection{Lao People's Democratic Republic}

As the Lao People's Democratic Republic (LPDR) is currently experiencing a period of high growth and development, so too are its efforts in Early Childhood Development (ECD) services because, similar to other countries in Southeast Asia, in LPDR, most ECD indicators are weak. These indicators clearly demonstrate a need to understand how to improve the effectiveness of existing services for young children and families to impact positively child outcomes. Implicated in effectiveness is the governance and finance of the systems that provide policy and financial structures to support services. Given the aim of the overall study to identify governance and finance mechanisms of national systems of health, education, and protection that are linked with improving access, equity, and quality of early childhood services (ECS), LPDR was included as a sample country because of the relevance of context with respect to ECD. 


\section{2.a. ECD and Governance Situation}

Lao PDR had made progress in areas of child survival (IMR 62 per 1,000 live births). However, this progress is not seen in other areas of health or nutrition where the immunization rate for measles is $41 \%$, and nearly $40 \%$ of children are stunted, suffering from chronic malnutrition. As problematic as these numbers appear, the situation might be much worse, as there remains a dearth of data from remote villages where poverty rates are much higher and seasonal food insecurity tends to be worse in rural areas. With respect to early childhood care and education (ECCE), enrolment rates in 2005 are at $8.2 \%$, which stands at a mere $0.7 \%$ of the eligible population. Furthermore, the quality of the programmes is poor, which is identified by the Ministry of Education as being linked to a limited teacher capacity, a result of having few teachers who have any formal qualifications or professional training.

The two main sectors for ECS in LPDR are government and non-government. With respect to government, the Ministries of Education (MoE) and Health $(\mathrm{MoH})$ are the primary ECS actors in LPDR as they provide the key programmes and services for young children and families. However, each of these ministries has their own architecture of departments and areas of operation. To design, coordinate and implement their programmes, MoE and MoH collaborate with associated ministries, such as the Ministry of Labor and Social Welfare and the Ministry of Justice (MoJ). To finance ECS, the two main government actors involved in ECD finance are the Ministry of Finance (MoF), which is the primary holder of government funds that allocates budgets to the line ministries, and the Ministry of Planning and Investment (MoPI), which manages official international and donor aid through their Department of International Cooperation (DIC). The health and education sectors have decentralized levels of offices and officers are at provincial, district and village levels. A smaller set of government actors include mass organizations, such as the Lao Women's Union and the Lao Youth Union. With respect to non-government organizations, there are three main categories: (1) international donors and aid agencies who primarily provide financial resources and support for ECD programmes, (2) international development agencies and international NGOs who provide technical support for programme implementation, and (3) international civil society organizations who implement ECD programmes (See Figure 6).

Lao PDR also has a broad set of policy statements across the key sectors of health, education, protection and national development, that are associated with governance of ECS. With respect to child rights, the 2007 Law on the Protection of the Rights and Interests of Children provides for the implementation of Child Protection Networks (CPNs) in all villages in the country, but is still in its infancy. Both the Lao government and UNICEF aim to scale up CPN's, hinting that there is great potential for future cooperation between the government and international agencies, especially in the field of advocacy and monitoring.

With respect to child care and education, the 2007 Education Law, which is implemented by the $\mathrm{MoE}$, has specific provisions for early learning standards to improve ECS quality. The current focus of ECD efforts in education is directed at the development and institutionalization of space and capacity for pre-primary education. Such plans are wholly contingent on existing structures throughout the country's primary school institutions. In the ESDF, the Ministry of Education proposed the roll-out of pre-primary 'community play groups' for those primary schools that are incomplete. Such schools may lack one or more grade levels and may not be available to handle 
space for a full pre-primary space, whereas complete schools will be provided with a pre-primary classroom. These efforts, as a whole, are a result of the Education for All Fast Track Initiative, where block grants have been allocated for the play groups and pre-primary classrooms. With the allocation of such funds for community-based efforts, Village Education Development Committees (VEDC's) are tasked with managing funds. Typically comprised of village chiefs, school directors, and representatives from various community groups, VEDC's are partners with the international support donor. Consequently, if and when funding discontinues, the VEDC likewise dissolves.

The health-based ECD services are supported by the $\mathrm{MoH}$ and several national policies and strategies, including the Expanded Program on Immunization (EPI), National Nutrition Policy, the Safe Motherhood Policy (2005), and the Strategy and Planning Framework for the Integrated Package of Maternal, Neonatal and Child Health Services (2009-2015). The governance of national ECS, through health and education, is decentralized through provincial, district and village levels of government. The Expanded Program on Immunization (EPI) provided the basis of ECD health services assessment for the study team. EPI's broad scope of health services, including, but not limited to vaccinations, antenatal and postpartum supplements, vitamin A supplements for children and breastfeeding instruction, allowed for the interaction with province and district representatives to cover many areas of ECD health issues. According to the Director of the EPI, $30 \%$ of vaccinations are provided in 'fixed' centres of healthcare, such as district health centres or village health clinics. The majority of vaccinations (70\%) are provided by 'outreach' mechanisms, or mobile clinics. According to a province EPI officer, these mobile clinics are conducted in the village centre or at the school, where vaccinations, deworming and growth monitoring activities occur.

During this time, workers attempt to educate present parents on the benefits of vaccinations and proper breastfeeding practices. Where available, Maternal and Child Health Centers act as community resources for parents and their children. As one of the fixed sites for vaccination, the Center also functions as the distributor of health information cards for vaccination record keeping and as the primary site for parent education. Such efforts focus on family planning, birth spacing and proper nutrition practices. Lao health programmes are predominantly funded by foreign aid and international donors. At the time of data collection, the EPI vaccinations were fully provided by foreign donors. Similarly, many health centres and hospitals were constructed as joint efforts between the Lao government and international agencies, such as JICA. While such partnerships are currently working to improve deficiencies in capacity, dependence on foreign assistance is recognized as a barrier to success of sustainable Lao national provision of its own healthcare.

Each sector operates independently of each other with little coordination noted, except in the development of national ECD policy at the national level and the delivery of services at the village level. For example, in the education sector, The VEDC is the most local branch of education representatives, under the Provincial Education Service and District Education Board.

Decentralization of responsibilities was not clearly understood as explained by the respondents in the study. Interestingly, while the VEDC is primarily responsible for handling programme funding, PES and DEB have assumed a more administrative role. Interviews with PES and DEB officers reflected their primary responsibility of data collection and reporting to higher levels 
Figure 6. Policy Architecture of Lao People's Democratic Republic ECS

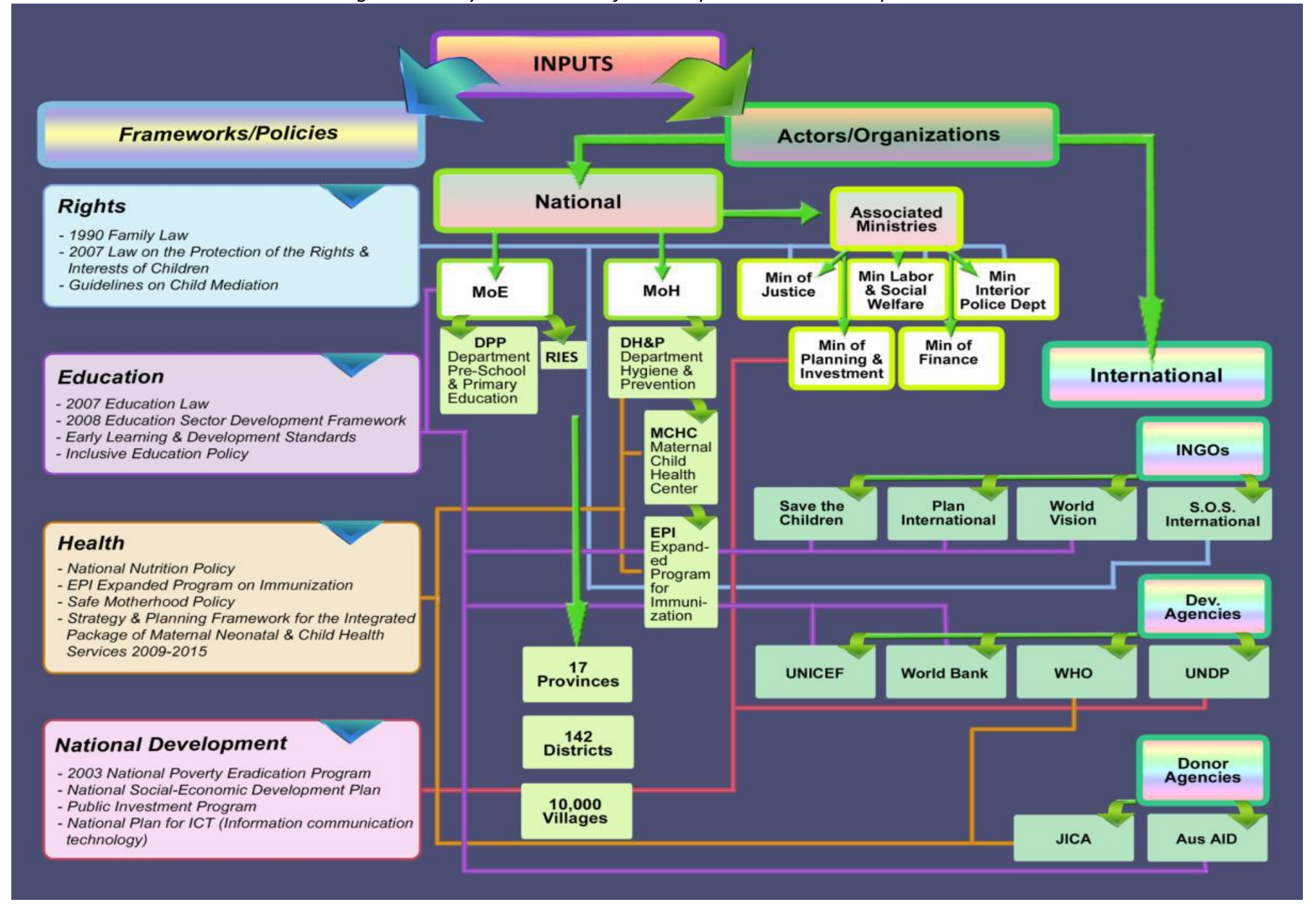


With respect to finance, the study was limited to the education sector, as it was difficult to obtain finance data from the health sector. There has been a steady increase in the overall budgeting for education, increasing to $\$ 110$ million by 2005 , an 80 per cent increase in a decade. In building on these increased investments, the 7th National Socio-Economic Development Plan (NSEDP) emphasizes the importance of education as a critical human capital element to move the country towards industrialization and modernity. However, with respect to access, as LPDR moves into implementation of the 7th NSEDP, the government already identified a funding gap of nearly \$143 million during the period 2011-2015, which means that access to programmes will be as limited as the current projected programmes and their costs fall below the expected revenues from the Lao government and the donor and development communities. Furthermore, the Education Sector Development Framework (ESDF) recognizes that the distribution of finances is not equitable, with poorer districts also receiving fewer resources, especially in terms of qualified teachers. The ESDF seeks to address some of these disparities with the goal to put in place fair and equitable financing mechanisms, taking into account affordability for Government and parents. Concurrently, with the goal of creating equitable financing mechanisms, the ESDF set forth the policy goal of increasing predictability in resourcing of the education sector. However, at the time of the study team's visit in 2010, it was not clear that these new financing mechanisms had yet been designed and implemented.

The two main sectors involved in ECS in LPDR are education and health; consequently they were the focus of the study. Four areas of findings are presented: first, an analysis of vertical coordination within the sector; second, horizontal coordination between the sectors; third, the importance of governance at the level of service delivery for equity, access and quality; and fourth, the critical importance of finance in a very low resource country.

Vertical governance within sectors was analyzed, taking into consideration the functions of decentralization. Interview data, collected at the 4 levels - central, provincial, district and village, yielded an interesting pattern of findings. The vertical governance of the health and education sectors, within the government, though independent of each other, showed similar patterns of results.

First, with respect to the accountability function of governance, the type of information that flowed from higher to lower levels was different from the information that flowed from lower to higher levels. The central to village level flow of information, i.e., a downward flow, was typically in the form of management memos and administrative notes, information solicitation and problem solving, when requested. The higher levels are not accountable to the lower levels of government for any function. Village to central level information flow, i.e., an upward flow, was typically comprised of data monitoring and the compilation of reports, based on the submission of information from the level just below. It was noted that accountability moves up from village to central, with each lower level accountable to the level just above. This governance structure, as expressed in the interviews, has a very hierarchical tone and one with little to no participatory decision making at the middle levels of government.

Another issue noted with this very hierarchical structure was that the provincial and district levels had very little coordination or knowledge of what the other sectors were doing. Additionally, there was a difference in the self-perception of roles and responsibilities of each level and what the 
other levels perceived that they were supposed to be doing. For example, district and provincial level officials saw their role primarily as managerial with an emphasis on moving information and inspection, whereas the central level spoke of these roles as more than just inspection, to include the supportive supervision and provision of technical expertise to the service implementers.

With respect to horizontal coordination, across sectors, governance was examined at the four levels of government as well. While the health and education sectors are both keenly involved in ECS, and very centrally engaged in services for children in the first few years of life, our data revealed that integration was a severe challenge. Therefore, we mapped out the structures of the health and education sectors to understand the bottlenecks in coordination. Our analyses revealed that the sectors were organized very differently, which made coordination difficult. In $\mathrm{MoE}$, while the department of preschool and pre-primary education is the lead within the ministry for ECD services, it is on par with the other departments. There is no formal structure for coordination or collaboration between the departments. The collaboration appears to occur on an as-need basis and is dependent upon the staff working in the departments. The $\mathrm{MoH}$ on the other hand, appears to have a less dispersed and more hierarchical structure with the EPI programme having to work under the Division of Mother and Child Health, which is under the department of Hygiene and Prevention. This means that the department head from the MoE, from the preschool and primary department's counter-part in the health sector, is a couple of levels below, administratively (see Figure 7).

Figure 7. Health and Education Structures
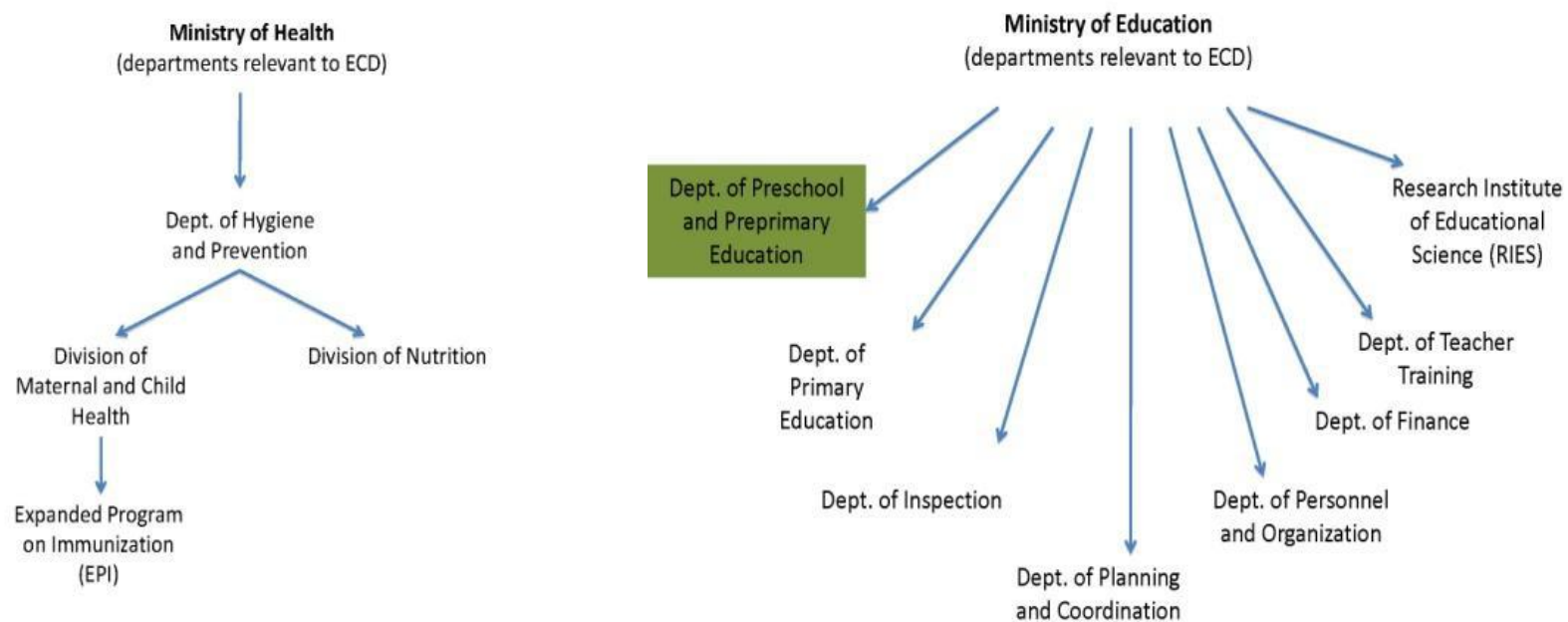

A third interesting pattern of findings shed light on the coordination between sectors at the level of service delivery. In LPDR, the village councils, led by the village chief, are the lowest level of governance and also the level of service delivery. Greatest coordination between sectors was noted at this level. The village authorities, and in part the Village Education Development Committees, appear to be the main implementers of the ECS and governance decisions. The village level system of governance in LPDR was astonishingly strong in the villages the study team 
visited. The strength of governance is being reported, based on the following characteristics. First, in every village, a village committee appeared to be in place, represented by several sectors, roles and members. This multisectoral composition of the committees added to its strength. Typically, the committees included the village chief, in some instances, a deputy chief, the village health worker, the school principal, the village elder, village party secretary, a security representative, a member of the LWU and parent representatives. This broad array of representation demonstrated an integrated approach to serving the needs of the families of the village from security to education. In addition to a broad representation, the village committees appeared fairly cohesive in their structure. Members appeared to understand not only their own roles and functions, but also those of the others on this committee. This mutual knowledge of responsibilities demonstrated that there was little overlap in work and a mechanism to cover for gaps. With particular reference to ECD, the committee was fairly well-tasked in attention to basic health, immunization, sanitation and hygiene.

Also unanticipated was the level of financial responsibility that the committee, in particular, the village chief, carried. While basic health services are free, such as immunization and elements of primary education, parents pay a fee for health services and fees for education. In addition, villages also get funds from higher levels of government to cover salaries and some infrastructure costs. Therefore, the village committee has a fairly substantial role in the financial decision making and monitoring of expenses and costs. The manner in which these governance roles were executed has a large impact on the quality of services. The more entrepreneurial village committees were better able to leverage their funds compared to committees that did not demonstrate such skills.

The final set of findings relevant to the study is the degree to which finance is the most important consideration for any function of governance in a low resource setting. The study in LPDR, which is a least developed country, revealed that the finance functions of systems and services overpower and undervalue the role of governance. For example, at the national level, the challenge of harmonization or alignment between international partner priorities and national government needs is a challenge; with respect to education, areas of expanding primary education were closely linked with international agency priorities and missions. Given that international partners bring the much-needed resources to programming, their priorities appear to be important agenda items. Education and health targets are closely aligned to MDG and EFA targets, even though the distance required to achieve them is very large. While these internationally accepted targets are important to move the world toward equity, the benchmarking process to achieve them has not been carefully considered or calibrated.

As a result, all countries, regardless of their starting point, have the same end point on the same time horizon. In the case of countries like Laos, they have to cover a far greater distance than other countries that started closer to the goal. Covering this distance in the allotted timeframe may or may not be achievable, but it does have ramifications for responsibilities of governance, with respect to understanding "whose development agenda is it?" At provincial and district levels, budgetary restrictions were cited as the main barrier to periodic evaluations and information collection for governance by the province and district officers. At the village level, one striking example of disparity in facilities of two primary schools, located a few kilometers apart, was linked with finance. Differences in construction, curriculum and materials were explained as differences 
in funding, where some schools receive private sponsorship and support from local community members.

Finally, even child attendance at school was linked with finance. While the majority of parents advocated for pre-primary education and space for their children, consideration of economic and agricultural aspects of rural life in Lao were to be considered. Absence of children from school during harvest time was explained by parents' needs for additional help in rice fields. To ensure school attendance, school directors implemented various methods of incentivization and monitoring. Subsidization of fees were provided in some villages, while other school directors took a more proactive role through community mapping and taking census of number, gender and ethnic background of children in villages served by their school. In LPDR, it appears that finance has a very strong influence on equity, access and quality.

\subsection{Kenya}

In 2012, Kenya, a vibrant East African country, finds itself at a turning point. After overcoming the 2007 political crisis, a new Constitution and a strong guiding policy document (Vision 2030) have been developed. As its title suggests, the latter entails a vision of state in which the country can and should find itself two decades from now, as well as a pathway towards that desired state. All sectoral policies must be aligned with this document, and children have a place in both Vision 2030 and the Constitution.

Kenya was selected for the study for several major issues that signal the need for more effective ECD services. First, population demographic trends indicate that while fertility rates in Kenya have dropped from 8.1 births per woman in the late 1970s to 4.6 in 2008, the annual number of newborns continues to grow (Kenya National Bureau of Statistics, 2009). This implies that the provision of equitable and accessible quality ECD services needs to be expanded as the services will continue to be in high demand. Second, with respect to equity, data indicates the existence of within-country income disparities. For instance, $74 \%$ of the population in North-eastern province is living below the poverty line, compared to $22 \%$ in Nairobi. Income distribution mapping suggests great differences among districts, possibly affecting access to quality ECS. Kenya's economic growth is predicted to average $4 \%$ in the coming years. Even if the ECD-relevant budgets remain constant as a percentage of GDP, these budgets will also grow $4 \%$ annually. This growth presents an opportunity to expand quality, access and equity in ECD services.

The ECD situation in Kenya, compared to neighbouring countries in the region, is good. For example, Kenya's infant mortality (95) and under-five mortality (158) rates are better than those for Sub-Saharan Africa (UNESCO, 2010). In terms of anthropometric measures, $20 \%$ of children are underweight, $6 \%$ are wasted, and $30 \%$ are stunted (UNESCO, 2010). However, it should be noted that while these numbers are better than those in the sub-Saharan region, because they are not geographically disaggregated they hide within-country disparities. For instance, on all indicators of child health, there are great disparities between the regions. In 2008/9, 32\% of infants in the North-eastern region were underweight, compared to $10 \%$ in the Nairobi region. These data suggest sharp disparities in some of the health outcomes analyzed and little net progress in the reduction of proxies for under-nutrition. 


\begin{tabular}{|l|c|c|c|c|c|}
\hline & $\begin{array}{c}\text { Low birth } \\
\text { weight }\end{array}$ & Underweight & Wasted & Stunted & Excl. breastfed 1st half yr \\
\hline Kenya & $10 \%$ & $20 \%$ & $6 \%$ & $30 \%$ & $13 \%$ \\
\hline $\begin{array}{l}\text { Sub-Saharan } \\
\text { Africa }\end{array}$ & $15 \%$ & $28 \%$ & $9 \%$ & $38 \%$ & $31 \%$ \\
\hline
\end{tabular}

Source: EFA Global Monitoring Report (UNESCO, 2010;322)

With respect to early learning, the GER in pre-primary education for children 3 to 5 years of age in 2007 was 60\% [National Bureau of Statistics, Kenya Facts and Figures 2007 and 2009 Census]. However, as with health, tremendous within-country disparities are noted in enrolment rates (see Figure 8 below).

Figure 8. Enrolment in Pre-primary Education: Number of School-age Children Enrolled by Year, 1999-2009

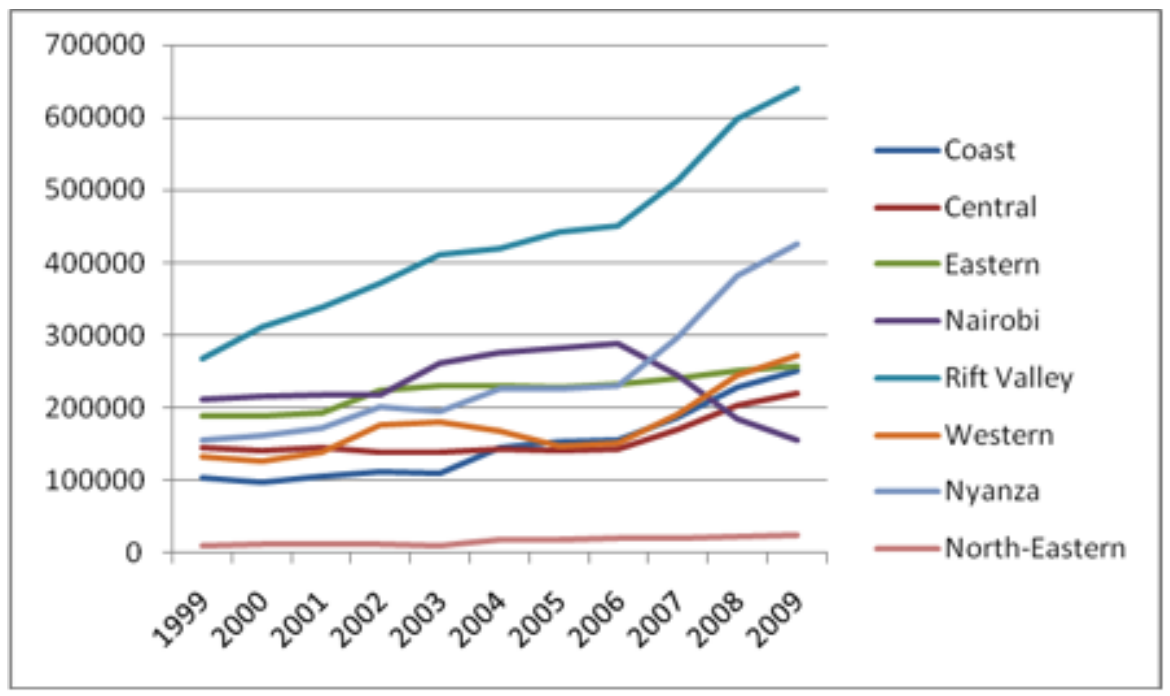

Enrolment Sources: Kenya National Bureau of Statistics (1999-2006) and 2009 Census (2009)

Finally, several population demographic shifts in Kenya have had critical impacts on ECD. Urban migration has not only transformed living conditions in urban slums, but is also changing extended family ties, thereby compromising the cultural support system for families. The spread of HIV-AIDS and the increasing number of orphans and single parent families has also spurred the disintegration of extended kinship networks. Another demographic trend is the increased participation of women in the labour force, more in particular in the formal (non-agricultural) sectors, which has led to younger siblings being left in the care of older sibling sisters, thereby limiting the chances for a good education of the older sisters. About $65 \%$ of all single mothers is said to be working outside the home, and for all women - married or not - the employment rate is 57\% (DHS, 2010:39). These shifting trends are important for the structure and types of ECS that need to be made available to support families and working women so that the education, health and development of the next generation are not compromised. 


\section{3.a. ECD and Governance Situation}

The policy architecture of ECD in Kenya is complex and broadly comprised of overarching national blueprints, ECD-specific documents, and sectoral policies and strategies that address all children. The first set of documents identified were overarching policy blueprints like the National Children's Act of 2001 and the National Children Policy that set macro-level directives for other child-related documents. Specifically, the National Children Policy serves as a framework to guide the government in achieving its commitment to Kenya's children through the implementation of the National Children's Act. These blueprints set national visions for all children, and provide platforms for the development of sectoral and inter-sectoral policies, policy frameworks, strategies, plans and guidelines.

The second type of documents identified were ECD policy frameworks, plans, guidelines and strategies like the National Early Childhood Development Policy Framework (2006), which is operationalized through the ECD Implementation Strategy and Monitoring and Evaluation Plan (2008/2009) and the ECD Action Plan (2010). The ECD Service Standard Guidelines (2007) address the roles of multiple stakeholders in "providing quality accessible and equitable services for young children". Together, the ECD-specific frameworks and plans represent strong policy intent to streamline and coordinate ECD services. Although the health, education and social protection sectors actively address child services, according to the ECD Policy Framework, education is the lead sector in ECD. For instance, ECDE monitoring and evaluation systems should be led by MoEST. Our content analysis of the documents revealed that the directives among the ECD-specific documents are complementary. For example, the ECD Implementation Strategy and Monitoring and Evaluation Plan provides overarching priority areas whereas the ECD Action Plan outlines key programmes and services to achieve the ECD Policy Framework goals. Because these documents are designed to work synergistically, a dissemination strategy, clear understating by multiple partners of their operationalization and harmonization of provisions are critical to their effective implementation and impact.

The third set of documents analyzed was sectoral and inter-sectoral programmes, policies and strategies that address all children and are inclusive of ECD. For example, the Ministry of Education generated a Sector Wide Approach for developing and funding the Kenya Sector Support Program (KESSP) 2005-2011, in order to actualize the government's vision for education in the country. ECD is featured in several of the main thematic areas and investment programmes of KESSP. Furthermore, policies like Gender in Education (2007) contain provisions that specifically address ECDE and the girl child. The National Special Needs Education Policy Framework (2009) includes guidelines that address all children. The National School Health Policy and Comprehensive School Guidelines (2007) focuses on the health provisions for children aged 5-19 but no guidelines are specified for ECE centres. Regarding early childhood health, the Kenya Essential Health Package to the Community: A Strategy for the Delivery of Level I Services (2007) and the Community Strategy Implementation Guidelines (Kenya Essential Package for Health to the Community, 2007) are operational frameworks and guidelines to build the capacity of community extension health workers (CHEW's), community-health workers (CHW's) and community-owned resource persons (CORP's). Several of the dimensions of the Community Strategy Implementation Guidelines are relevant to ECD. For instance, three out of the six specified target cohorts address health needs of children 0-8 (pregnancy, delivery, and first two weeks of life; two weeks to five 
years of age; and five to 12 years of age). Within these cohorts, CHEW's, CORP's, trained caregivers, trained teachers and trained parents are specified as the human resources required for the provision of service and activities of the package. With respect to social protection, Kenya's Cash Transfer Program for Orphans and Vulnerable Children (CT-OVC) delivers cash to families, which they can use to pay for food, clothes, and services such as education and health. The impact of CT-OVC on ECD outcomes is yet to be determined.

Together, our summary of documents suggests that a combination of blueprints, ECD-specific documents, and sectoral and inter-sectoral policies, programmes and strategies in the last 5 years have generated a complex EDS policy architecture in Kenya. Despite gaps in some documents regarding ECD provisions (i.e. health guidelines for ECDE centres in the National School Health Policy are lacking) and the need to harmonize the operationalization and dissemination of plans (i.e. ECD Implementation Strategy and Monitoring and Evaluation Plan and the ECD Action Plan), our analysis suggests a strong policy intent to achieving quality, access and equity of ECD in the country.

Figure 9. ECD Policy Architecture in Kenya

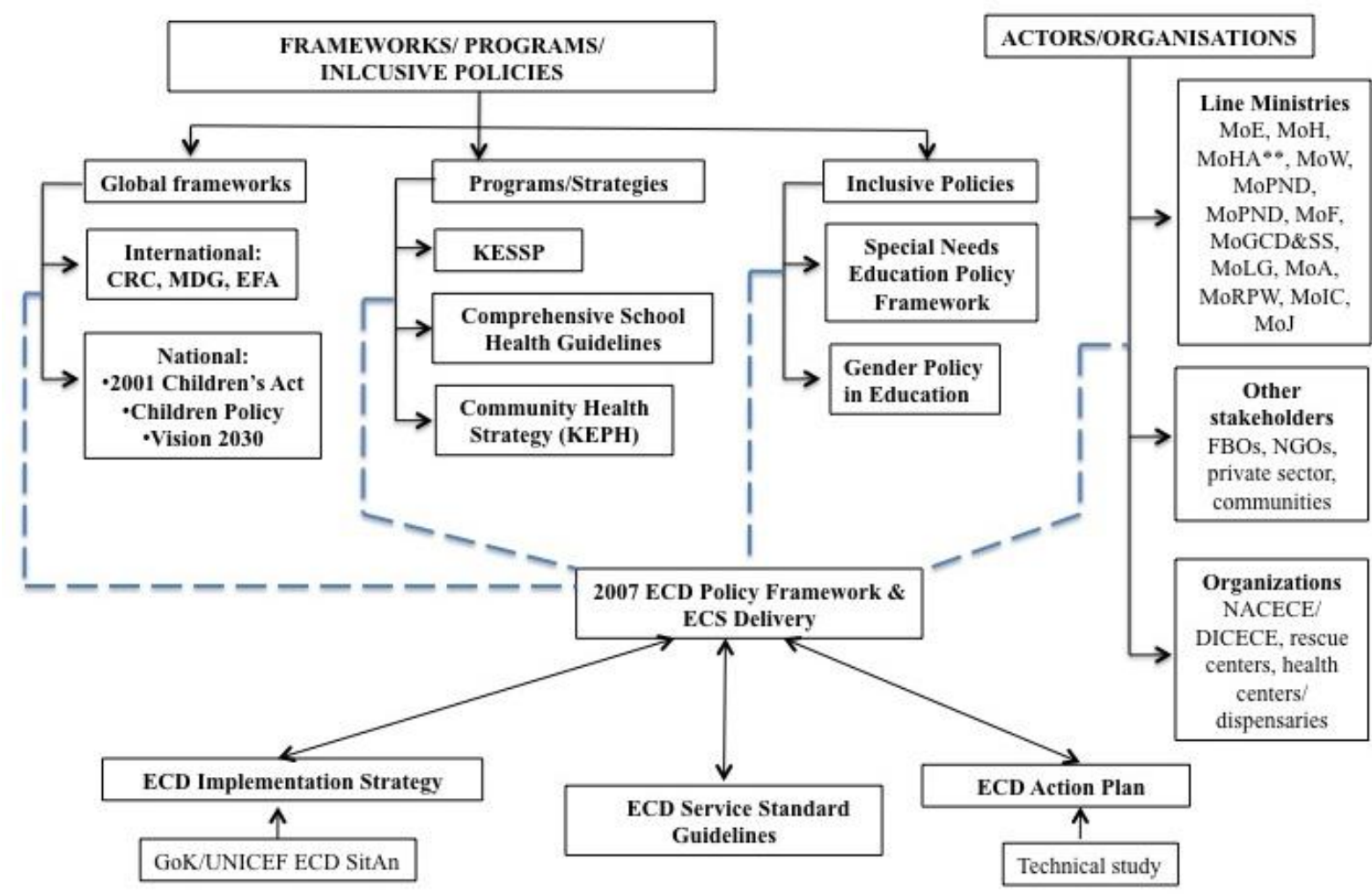

The policy architecture of ECD in Kenya is complex and broadly comprised of overarching national blueprints, ECD-specific documents, and sectoral policies and strategies that address all children. The map broadly describes the documents, key actors and organizations identified in the provision of ECS.

With respect to ECD governance, several government actors play a central role in ECD. While these actors have sectoral affiliations in health and education, for example, a unique and important aspect that emerges in Kenya is the existence of intersectoral councils, focused on improving 
children's well-being. The National Council for Children's Services (NCCS), a semi-autonomous intersectoral government agency, was established under the Children's Act of 2001. Its key role is to plan, regulate and coordinate children's rights and welfare activities. NCCS established Area Advisory Councils (AACs) to address various issues on rights of children in their areas of operation. AACs represent the NCCS at district, divisional and local levels. AAC members include actors from line ministries, NGOs, community base organizations (CBOs), faith-based organizations and the business community. The chairperson for each AAC is the District Commissioner and the Secretary is the District Children's Officer. Performance standards for AACs in Kenya were streamlined by guidelines released by NCCS in 2006 .

With respect to finance, we focused on budget allocations for ECD and highlight two patterns. First, the education sector in Kenya receives a significantly higher percentage of the national budget compared to health and social protection. While a difference between education and health spending is also often noted in other countries, the difference elsewhere is not as great as in Kenya where education receives (according to national data pertaining to 2006-2007) $28.5 \%$ of the government budget against a mere $5.8 \%$ for the health sector. Likewise, a global comparison indicates that Kenya was the 12th largest spender on education in the world in 2005, while the country ranked only 142 nd on health spending.

Second, while the spending on education appears large, it is primarily spent on basic education. However, given that this large percentage is accorded to education and that education is the lead sector for ECD, if budget allocations would be revised to provide slightly more funding for preschools and pre-primary, that would significantly impact some of the limitations in the effectiveness of service provision for young children. Striking a better balance between primary and pre-primary education within the budget would enable the latter sector to address some of the problems and issues of disparities.

Our analysis of Kenya's ECD policy architecture revealed four overarching governance mechanisms to promote the effectiveness of implementation and access, quality, and equity of ECS: (i) identification of a coordinating body for ECD and provisions for its key functions; (ii) multisectoral approaches to ECD and mechanisms for horizontal coordination; (iii) establishment of decentralized institutional arrangements; and (iv) service integration and community participation. We triangulated data from the content analysis of sampled documents, key informant interviews, and focus group discussions to explore the ECD policy architecture in the country. Figure 10 displays the key informant interviews that informed our analyses of strengths and challenges to fulfilling the four mechanisms identified. 


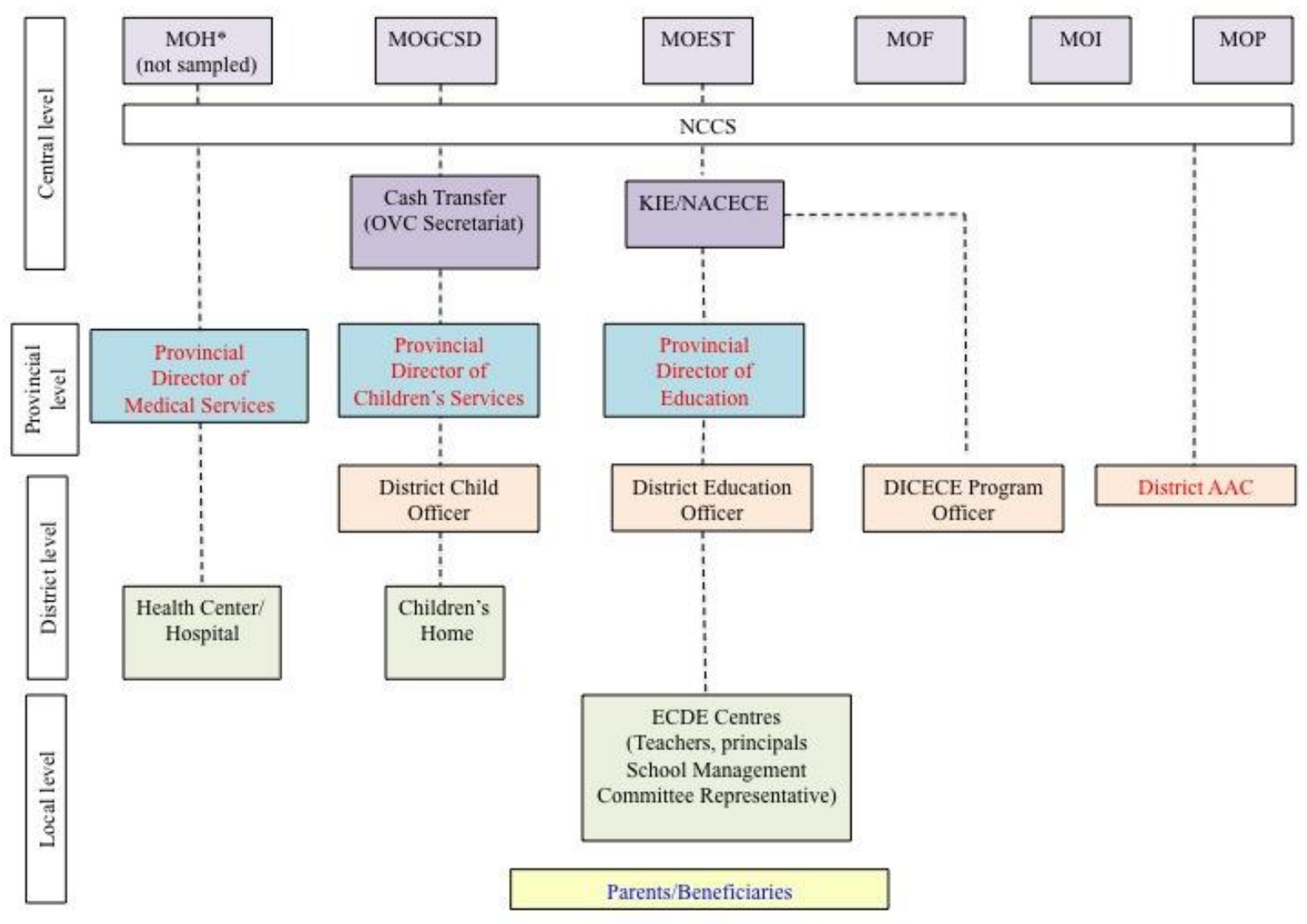

Key informants were identified at the national (central), provincial, district and local levels. The figure illustrates the general organizational structure of the study sample. Provincial-level informants and AAC members were only interviewed in the North-eastern Province (red). The parent/beneficiary focus group discussion was only conducted in the Eastern Province (blue).

1. Identification of a coordinating body for ECD and provisions for its key functions. Coordination was examined, both with respect to horizontal and vertical dimensions (see Figure 11). In Kenya, ECD-specific documents like the National ECD Policy Framework provide an integrated statement and structure for ECS provision. Establishing NCCS as the coordinating body for ECD in the country and identifying key functions (e.g. promotion of partnerships with local academic institutions, strengthening vertical coordination of ECS through AACs, and developing systems to centralize data and support data flow) reflects policy intent to move ECD from a sectoral to a more comprehensive structure. Interviews with key informants revealed that NCCS designed strategies that could drive the triumvirate of access, equity and quality in ECD by propelling advocacy efforts and providing policy guidelines, operational links, and programme management support. Some of the strategies include: (a) policy drafting and advocacy - NCCS has played an instrumental role in the drafting of documents (e.g., ECD Action Plan) and promotion of the alignment of national documents (e.g., Children's Act and the New Constitution) to drive coordinated ECS provision; (b) leading ECD research - NCCS has partnered with academic and multilateral organizations to bolster local knowledge on ECD; (c) vertical coordination = NCCS provides linkages from central to local levels through the operationalization of AACs; and (d) horizontal coordination - the multisectoral 
composition of NCCS provides an open forum at the central level for the orchestration of integrated ECD activities while receiving information from local levels.

Data from key informant interviews suggested that the communication channels between districts AAC's and NCC's are well established and that the mechanisms for flow of information to the central levels are well defined. However, the current status of ECD in Kenya suggests that despite the facilitated communication, there are gaps in the implementation and responses to ECS needs. For example, district AAC informants reported several challenges to their functions as they relate to ECD. Some of the limitations included limited funding for ECDE centres, limited technical support for activities related to Child Protection Units, and weak communication with divisional and locational AACS.

Greater support for NCCS is required to lead the integrated execution and implementation of the ECD Action Plan, systematically identify gaps in service provision (track coverage and quality of services provided) and coordinate activities among multiple sectors. For instance, informants revealed that Performance Contracts are critical drivers of the operations within NCCS and other government bodies. A Performance Contract is "an agreement between a government and a public agency which establishes general goals for the agency, and sets targets for measuring performance and provides incentives for achieving these targets. They include a variety of incentive-based mechanisms for controlling public agencies". ${ }^{2}$ At the time when this study was conducted, ECD was not part of NCCS's Performance Contract. ECD could be integrated accordingly as a way to increase the efforts devoted to ECS oversight and coordination. Finally, AACs provide a unique venue for oversight, advocacy and support to ECS. Their multisectoral composition and local representation is a space whereby needs, demands, and challenges to ECS delivery can be systematically and periodically addressed. It is critical to support the fulfillment of District, Division and Locality AACs and ensure that the multisecoral and multilevel representation is fulfilled.

Figure 11. Illustration of Horizontal and Vertical Coordination of ECS in Kenya

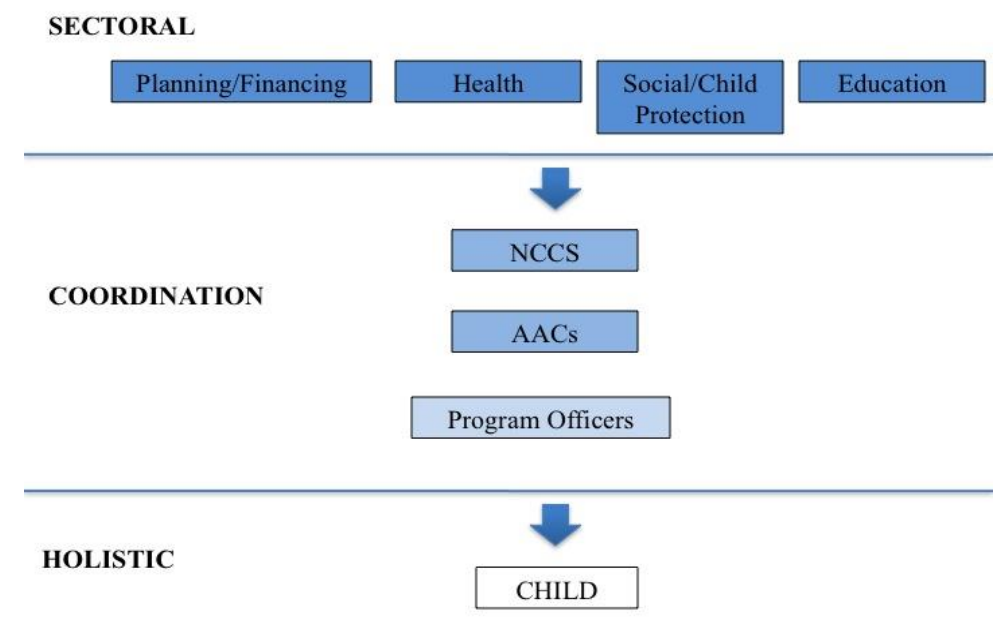

\footnotetext{
${ }^{2}$ Tivedi, P. Performance Contracts in Kenya: Instruments for Operationalzing Good Governance. World Bank Report.
} 
2. Multi-sectoral approaches to ECD and mechanisms for horizontal coordination. At the provincial level, Provincial Directors of Health, Education and Child Services provide leadership for implementation of ECS in their respective areas of jurisdiction. At the district level, District Officers of Education (DEO) and Health (DMOH) and District Child Officers emerged as key entities for the coordination of ECD-related activities on the ground (for instance the School Health Policy provisions the DMOH and the DEO as coordinators of the policy). Furthermore, accountability for distribution of ECE guidelines, policies, and curricula lay primarily with the DEO and the Head Teacher. During our ECD Centre visits, the DEO and DIECCE programme officers were identified as key actors where central policies met local accountability and coordination. For instance, the DEO and DICECE programme officer ensured training and registration guidelines were known, and were responsible for overseeing their implementation. One DICECE programme officer reported being involved in activities regarding child protection and child health, suggesting their potential to participate on multiple dimensions of child well-being. The interviews revealed that support to DEOs along with other relevant local governance bodies (like School Management Committees), could be strengthened to maximize their coordinating and oversight functions in education and community settings. In sum, District Officers (DMO, DPHO, DEO, DCO, and DICECE programme officers) are critical agents who are very close to young children and families. Support and oversight for the programme officers is fundamental to the implementation of comprehensive ECD guidelines and standards.

At the policy level, Kenya's ECD Policy Framework represents a clear effort to move ECD forward towards a comprehensive system of ECD and is a blueprint for coordination. An emergent theme from key informant interviews was that on the ground, coordinated activities were "infrequent and difficult to operationalize". Despite the representation of multiple sectors in drafting of the $E C D$ Policy Framework, ECDE implementation Strategy, and ECD Action Plan, ECD services are largely funneled through education centres/facilities with little presence from other sectors. Our field observations suggest that planning of ECS still largely occurs independently within the line ministries with the exception of some activities (e.g. health-checks, nutrition programmes and deworming in ECD centres which are an alignment of $\mathrm{MoE}$ and $\mathrm{MoH}$ operations). It is necessary to strengthen the understanding of coordination on the ground and mechanisms to operationalize programmes.

3. Decentralized institutional arrangements in the early childhood education sector. The establishment of NACECE, DICECE, the ECD Unit of the Directorate of Basic Education, the ECD Unit of the Division of Quality Assurance, and deployment of District Quality Assurance Officers are initiatives to propel quality in teacher training and curriculum development. The release of standards and guidelines and the existing institutional arrangements for their implementation are key strategies to pursue quality (through the delineation of comprehensive ECD standards of practice) and equity (through the mandated delivery of guidelines and oversight of practice in all centres via programme officers). According to a 2008 ECDE Situational Analysis, although NACECE/KIE have developed comprehensive national guidelines, they are not readily accessible to ECDE teachers, especially those in small and remote ECDE centres in rural communities (Abagi, 2008). In agreement with those findings, our interviews revealed that there is variability in the level of implementation of the guidelines and that there are gaps in the accountability systems to 
ensure implementation. Furthermore, not all school principals were aware of the existence of the ECDE guidelines. In addition, the ECED Situation Analysis of 2008 found that out of 181 ECDE teachers 21 (or 11.6\%) were untrained (Abagi, 2008). Despite the progress in teacher training, significant challenges remain: one of the DEOs interviewed, highlighted the difficulties in financing in-service training (teachers pay high out-of-pocket fees) and limitations in the infrastructure for conducting training sessions locally.

Regarding decentralization and processes of data collection and flow, the ECD Implementation Strategy notes that with regard to ECE "data flow and linkages at national, provincial, district and community levels should also follow the existing channels which are being used in the current MOEST EMIS/DEMIS frameworks for reporting and feedback". Our interviewees revealed that fulfillment of the reporting systems provisioned in the ECD Implementation Strategy is limited. For example, respondents reported that schools collect data on enrolment and retention records but that not all head teachers submit reports regularly. This suggests that MoEST could further strengthen the submission protocols of local reports (i.e. DEMIS forms) and utilize that information to track progress and gaps associated with the implementation of ECS (for example enrolment of special need children, compliance with health and nutrition checks, tracking health outcomes, tracking progress of the implementation of the Gender in Education policy provisions, etc.).

Furthermore, among our key informants, there was a notable lack of awareness of the standards developed for children 0 to 3 years of age. Although the ECD Unit of the Directorate of Basic Education was appointed to lead key efforts in relation to ECD (formulation of policy guidelines, registration of preschools, coordination of data collection, funding, and provision of trainers) little emphasis was placed on programmatic goals, attributed to quality of caretaking in nurseries and children younger than 3 years of age. Lack of equitable dissemination of ECDE guidelines down to the local level appears to be a challenge to improving programme quality. A focus group with mothers of young children in Machakos (Eastern Province) revealed that nurseries are unaffordable to them and that they are therefore unable to pursue jobs outside the home. Mechanisms for parenting education were reported to be scarce. It is necessary to bolster equitable access of quality nurseries and/or education to young mothers in communities in which these services are needed.

4. Service integration and community participation in the health sector. Evidence suggests that early childhood integrated interventions are the most effective in improving child outcomes (Engle, et al., 2011). The Community Strategy Implementation Guidelines establishes a framework for the operationalization of the Essential Health Package Strategy and integrated health interventions. Together, the Guidelines and the Strategy spell out a set of principles to promote physical wellbeing and holistic development of children (e.g. the documents contain provisions on stimulation to promote social, physical and intellectual development and attachment). Our interviews with district public health nurses revealed that the implementation of $\mathrm{C}-\mathrm{IMCl}$ was strong in the sampled centres, suggesting the existence of good mechanisms to implement guidelines and healthcare protocols. This illustrates policy intent to integrate practices that promote child health and development and that operationalize integration of interventions. Furthermore, ECD programmes should strive to ensure they are responsive to local needs by working closely with communities, giving them leadership roles, and involving them in service provision and oversight. The Community Strategy Implementation Guidelines and the organizational structure of Kenya's health 
sector heavily rely on the community. Interviews revealed that community health workers are recognized agents of health promotion and that community health extension workers, by providing a diverse range of services, could represent integrative mechanisms for the provision of ECS.

Despite these efforts, there are infrastructural and operational challenges that compromise the impact of these provisions. However, infrastructural challenges remain an obstacle. For example, although prenatal care and healthcare for children under- 5 is free, we noted gaps in the provision of services such as emergency obstetric care (EmOC). Field observations in Garissa revealed an under-equipped EmOC facility in a centre with few resources to displace patients to a nearby hospital in case of an emergency during delivery. These larger issues of access and quality of healthcare need to remain at the forefront of aggressive national interventions and investment. Regarding community involvement, the perception of the informants was that community health and extension workers require a stronger incentive system and operational support. Further research is needed to assess the strengths and weaknesses of the integrative and community approaches as well as to identify mechanisms to strengthen their implementation.

Regarding ECDE finance, Kenya also afforded an interesting case study. Given the central role of the education sector in ECS, our study focused on the education budgets. As per the KESSP for 2005-2012, the allocation of finance is directly to communities. Almost $75 \%$ of ECDE funds are distributed directly to communities through grant mechanisms. Therefore, the role of community leaders in the governance of ECS finance is critical. The community leaders and authorities receive the grants, disburse the funds and manage the budgets. As noted earlier, on indicators of early learning, there are great disparities in Kenya in pre-primary enrolment. Given the mechanism in place to fund communities directly, our study suggests that pro-poor criteria should be included in the funding mechanisms that will allow for the most disadvantaged communities to improve their ECD outcomes. Also, the spending criteria should be flexible to allow for communities to disburse funds needed for their individual community needs. This recommendation is made with the provision that community leaders are trained in the governance of finance to ensure effective and efficient use of funds. This association between community level funding can have important implications for improving the access, quality and equity of ECS.

In summary, the three country case studies provided an excellent opportunity to investigate the governance of ECS. While each of the countries is contextually quite different with respect to socio-economic, political and cultural contexts, the individual study investigations revealed a trend in the findings which are presented in the next chapter.

\section{STUDY FINDINGS: CROSS COUNTRY PATTERNS}

In this chapter, we focus our analyses on the themes and patterns of findings that emerged across the three countries. Despite wide variation across the three countries in ECS provisions and country socio-economic and political structures, the analyses yielded interesting similarities. The patterns in the findings are presented in the following five sub-sections, on (1) main actors in ECS; (2) horizontal and vertical dimensions of governance; (3) the link between national policy and coordination of governance; (4) local governance structures as key levers for improvement of ECS; and (5) the implications of the beneficiary perspective in governance. 


\subsection{Who Are the Main Actors in ECS and What Are the Implications for Capacity Building?}

ECS are complex because they cover a large age range, prenatal to 8 years of age, and cut across sectors thereby involving a range of actors. Our first step in each country study involved identifying and mapping the main ECD actors in the country. The significance of this study is that it provides a set of tools to systematically identify the main players in the system that provide services to young children and families, their role, and their interrelationships across both administrative levels and sectors. Our analysis highlighted the need for different forms of capacity building across these actors.

The first level of identification focused on the sectors involved in ECS. For the most part, this basic analysis has been long standing with the traditional sectors including health, education, protection and social welfare. Across the three countries, this model was noted with no significant differences. However differences were seen across countries in the composition of actors within each sector, with implications for capacity building.

Within each of these sectors there is a range of key partners. For example, typically for early learning programmes, in addition to the Ministry of Education, there are international NGO's, national NGO's, community based and faith-based groups and the increasing private for-profit sector. The mapping in LPDR indicated that each actor in the sector had a role, although that role was not clearly known and not understood by the other actors. For example, the MoE or government actors were involved in setting policies, regulations, guidelines, standards, and curriculum development and international NGOs provided technical and financial functions for ECE programmes. The early learning services were implemented by a range of additional actors - who included local NGO's, and INGO's, and the private for-fee sector. In effect, each of these actors had a role to play in the design, implementation, coordination, training, monitoring and finance of ECCE. However, until their roles are clearly mutually understood and differentiated, the system cannot move forward efficiently.

In Cambodia, the early education framework was slightly different with three models being implemented at national scale (State Preschool; Community-Based Preschool and the Home-Based program). Due in part to limited direct government funding, and concentration of the MoE on the most expensive centre-based model (state preschool), NGOs had stepped in to expand access for the disadvantaged through the other two, lower-cost models. For each of the models, though the sponsorship was through the MOE, the governance functions of design, finance and quality regulations varied across multiple INGO, community-based organizations and communes. This means that capacity building in each of the three programmes looked very different, with for example no joint professional development across them. In Kenya, yet another model was noted where MOEST had generated a Sector Wide Approach for education. In addition to that sectoral strategy, the ECD Policy Framework had provisioned MOEST as the lead entity for ECDE. Therefore, the success of implementing operational and quality guidelines in ECE relied heavily on the ability of the Ministry to use decentralized mechanisms of governance and apply capacity-building strategies to key actors (e.g. NACECE, DICECE, District Quality Assurance Officers or DQASO, and Provincial and District officers) to bolster and scale-up quality ECE in the country. In sum, improving access, equity and quality requires an understanding of all actors who could be 
responsible and specifying their particular roles. The multiple functions of actors differ greatly across countries even though they fall under the broad traditionally understood sectors.

Second, within each actor, e.g., MoE, there are multiple departments that need to work together to fulfill the governance functions. For the most part, in the ECD literature an actor is treated generically, e.g., $\mathrm{MoE}$ or $\mathrm{MoH}$. Our work showed that a greater specification and identification is required of each actor if we want to influence outcomes. Within the MoE, of LPDR, for example, we noted that four different departments were involved with the different governance functions of the pre-primary programme: (i) the department of preschool and primary education was responsible for the design, development and implementation of the service; (ii) the Research Institute for Educational Sciences was responsible for the content and curriculum; (iii) the department of teacher training was responsible for capacity building; and (iv) the department of budget and finance for providing funds from within the education budget for this programme. This level of specification, through our governance maps, enabled a clearer understanding of how to influence system level outcomes, depending on the identification of the challenge. For example, in LPDR through the interviews it became apparent that the department of finance in MoE was not well informed of the pre-school and primary programme - this then had implications for improving access and quality.

With respect to similarities across countries, we identified disparities in capacity across actors in ECS in each of the countries. We highlight the example from Cambodia to illustrate the pattern. In Cambodia the international NGO capacity for budgeting and planning were in some respects higher than in the central government ministries, due in part to the scale of funding being much larger on the part of these NGO's. Yet the international NGOs relied at the subnational and local levels on the government administrative hierarchy for implementation. The building of capacity across sets of government, NGO and civil society actors and across national to local levels is not a centrally held responsibility, and therefore, national action planning should take into account this issue across them. This represents a perhaps novel alternative to the traditional definition of crosssector analysis.

\subsection{Dimensions of Governance: Horizontal and Vertical Coordination}

It is a well-established fact that ECD requires coordinated services because it addresses the holistic development of children including health, physical well-being, education, development, protection and overall well-being. However, this conceptualization of coordination may not be well understood or operationalized. For example, at the service level, one of the most widely implemented models is "Integrated ECD", which combines several different approaches, e.g., nutrition and stimulation (Walker et al., 2005). However, this is only one aspect of coordination and focuses primarily on the service level. Other work on coordination in ECS has taken a linear approach, one that spans initial single-sector approaches through cross and multi-sectoral into comprehensive (Vegas et al., 2010). Our study suggests that while models are applicable to ECD, they might offer limited explanatory power in truly understanding governance of ECS across both vertical (national to local) and horizontal (across sector; across geographic and jurisdictional areas) elements. 
In order to systematize our analysis of governance, which incorporated both horizontal and vertical elements, we explored multiple strategies but most centrally policy architecture mapping. This is a developing method in the field of ECS - therefore we present some variety in our strategies of policy architecture mapping. Each map integrated the main actors of ECS in a given sector or service with attention to links between national, subnational and local levels, as well as links across sectors (note that due to the limitations of our study resources and therefore regional and local sampling, we were not truly able to map links across geographic subregions).

Our analyses of the policy architecture of ECS revealed that there are two dimensions to coordination for ECS and that these need to be examined simultaneously to determine how to strengthen systems for service delivery. The dimensions are horizontal coordination and vertical coordination. Horizontal coordination occurs at a particular level of the administrative hierarchy and includes all the main actors who are involved in ECS. Vertical coordination, on the other hand, includes all the actors within the system, from the highest to the lowest level of government. While vertical coordination has been well studied through models of decentralization, devolution, delegation, and deconcentration (UNDP, 1999), and calls for intersectoral coordination are frequent, simultaneous analyses of vertical and horizontal governance are lacking in the ECS literature. We believe this is one of the contributions of our study. Furthermore, we also noted that this simultaneous analysis revealed an interesting and unexpected pattern of similar findings rather than differences across the 3 countries.

In each of the three countries, the greatest level of coordination and even awareness of the need of coordination across sectors, were at the national and, in Cambodia and Lao, local level of government. It was typically at the central (national) level interviews that the respondents indicated that they engaged directly in intersectoral efforts, some respondents presenting information that defined these efforts. Two mechanisms were observed - national action planning, and the work of central coordinating councils responsible for ECS. As an example of the first, the central government level respondents in Phnom Penh described how the process of developing the National Policy for Early Childhood Development as integrative across ministries and involved an unusual level of collaboration across leading policy makers in the national government as well as local and international NGO's. The National Action Plan, which was being developed during the time of the study, similarly indicated involvement from stakeholders across the 11 ministries and major NGOs supporting ECD in Cambodia. Similar understandings were obtained through interviews in Kenya and LPDR. As an example of the second mechanism, the Kenyan government established a national coordinated body for children's services with strong representation of the ECS sector.

At the local level of government (the village, commune or community,) again a similar articulation of coordination was noted. In all three countries, interviews with the village authorities indicated coordination, which was either the result of that fact that they understood the need to integrate health and education services for young children and families or that all service decisions rested with one person, e.g., the village chief or a group, e.g., the village authorities. The village authorities and specifically the structure of governing councils sometimes ensured representation from several sectors, thereby leading to a greater coordination in services. For example, in Cambodia, the commune councils in the villages were the key governance institutions at the lowest level of government, and a direct result of the national decentralization process. The local 
governance of ECD occurred through representation of the Focal Point for Women and Children, as well as representatives of health and education. With the addition of some local budgeting authority and capacity (through the chief and the commune council clerk, who typically handled records of budgeting decisions and actual spending), this model is a strength for ECS in local governance as it allows for local participation, ownership and response to contextual needs and situations. In Kenya, District AACs were comprised of multiple actors who engaged in issues regarding child health, protection and education under a multi-sectoral venue. However, interviews revealed that engaging village networks (which are local-level forms of organized representation) was challenging for Districts AACS. Furthermore, District Officers (of education, health, and protection) worked closely with beneficiaries and public institutions. Therefore, in Kenya we observed key roles for ECD at the district level, along with a need to engage the local communities and further strengthen the support and coordination at central or national and provincial levels.

Our simultaneous vertical and horizontal analysis showed that the subnational levels between national and village, demonstrated the weakest horizontal coordination at mid-levels (namely, provincial and district) of government. Typically, at the district and provincial levels, staff in health and education sectors did not work across sectors in the governance and implementation of ECS. Their offices were often physically separated, and neither representative bodies nor joint action planning occurred to the degree that we observed at local or national levels. In each of the country case studies, the interview data revealed that middle levels of government typically see their role as one of supporting information flow and communication within the sector and monitoring and supervision to some extent. The compliance and supervisory/monitoring roles of these intermediate levels were almost entirely vertically focused (that is, compliance oriented upward to higher administrative levels; supervisory/monitoring roles oriented downward towards lower administrative levels). Few incentives existed at these levels for staff to ensure horizontal coordination. There was little to no mention of cross-sectoral collaboration in their job description, tasks or implementation of ECS. It should be noted that in Kenya, the presence of Provincial Children's Officers, District Children's Officers, DICECE Program Officers, and District and Location Area AACs, signaled at the emergence of vertical and horizontal coordination mechanisms at the mid-levels.

This pattern of findings has potential implications for strengthening systems of ECS. First, it provides a greater understanding of "coordination" with respect to ECS. Given the focus on integration and the need for inter-sectoral efforts for the success of ECS, this study suggests areas that can be strengthened. In particular, further ECD work should focus on middle levels of government to strengthen coordination. This may be a challenge for human capital development the competencies for leadership at middle levels of public systems are distinct from those at the national and local levels. Few administrative or leadership development programmes provide specific training for middle-level management. In addition, in each of our countries leadership capacity and human capital was concentrated in the capital city. Incentives to draw talented management into the provinces were generally lacking in each of the three countries, at least as far as early childhood services were concerned. 
Thus far, most of the attention in global ECS has been directed to national/central levels through awareness and capacity building on the value of coordinated approaches. The results of this work are starting to become apparent in the form of national policies, action plans and guidelines at the central level. However, for effective implementation of these statements and effectiveness of their impact on the system to achieve equity, access and quality, attention is required at the middle levels of government. Given the exploratory nature of this study, and the primarily lowincome country sample, this pattern should be examined in other countries as well to establish its validity and generate guidance on how to approach the challenges of middle-level government capacity and coordination. In addition, the NGO focus has generally not been so much at this level, but more the national and local levels - leaving lacunae across the public and NGO sectors in this key link in policy implementation.

\subsection{Influence of Policy on Coordination Function of Governance}

A unique set of findings was obtained in Kenya and Cambodia regarding the role of established policies in promoting the governance function of coordination. Such policies were not found in LPDR.

In Kenya, as described earlier, the country has passed a Children's Act of 2001, the National Early Childhood Development Policy and ECD Implementation Strategy thereby indicating strong policy support for young children's well-being. The content analyses of the policies revealed that the Children's Act of 2001 has led to the creation of an intersectoral council, the National Council for Children's Services (NCCS), a semi-autonomous government body. The role of NCCS is to plan, regulate and coordinate children's rights and welfare activities. Further, the NCCS established Area Advisory Councils (AACs) to address various issues on the rights of children in their areas of operation. AAC's represent the NCCS at district, divisional and local levels. Similarly associated with the ECD policies, the country has established a National Committee on ECD (NaECD) that works closely with NCCS. Also, in Kenya, sectors have established ECD bodies, under policy provision, e.g., the MoEST has the National Center for Early Childhood Education (NACECE), established in 1985, and the District Centers for Early Childhood Education (DICECE) are responsible for preschool education including local training of trainers, and mobilization of communities with regards to health, nutrition, and education for young children. NACECE has further responsibilities for preschool curriculum and material development, training of personnel and professional support to the district, city, and municipal centres for Early Childhood Education.

We combined this analysis with the interview data to learn that the NCCS plays a key role in ECS coordination and advocacy and that the AACS are important for the flow of information and communication. While the efficiency of these institutions was also questioned in several of the interviews, identifying challenges of capacity and resources in effective function, the existence of such institutions presents useful examples for coordination in ECS. Currently, in the field there are very few examples of coordinating bodies for ECD that are mandated via policies; either these bodies develop organically or have a temporary presence to complete a specific task. The strength of the institutionalization of coordination in Kenya is noted in the policy support for the agencies and in the clear operationalization of roles and responsibilities. While the implementation is not satisfactory, as noted by some respondents, organizational structure and operationalization of roles for coordination offer a very useful example for intersectoral approaches to ECS. 
In Cambodia, a national governance policy without origins in ECS had implications for the creation of an institution that oversees ECS. The decentralization and deconcentration (D\&D) reforms undertaken by Cambodia, in the last decade, led to the creation of commune councils, aimed at increasing the capacity for local governance. The reforms were a direct response to the prior history in Cambodia of complete loss of sovereignty and governance structures under the Khmer Rouge, as well as the subsequent control of governance by Vietnam. These commune councils were involved in the primary models of ECS in the country, e.g., State-run Preschools, Community preschools, and home-based services, albeit to different degrees. For example, the Commune Committee for Women and Children (CCWC), which includes the Commune Chief, the Second Deputy, the Focal Point for Women and Children (CCWCFP), the Commune Clerk, the Health Center representative, a representative from the school(s) is responsible for ensuring that benefits and services are provided for women and children, and that these services and benefits are received without discrimination (Ministry of Interior and UNICEF, 2009), promoting equity and access. This institution has no direct connection to ECS, however is clearly responsible for it, based on policy directive and national reform. While this institution is important, our study revealed that the Focal Point for Women and Children, as well as the local health representative on the Commune Council are key individuals for ECS. However, these Focal Points are usually unpaid volunteers and without any voting rights therefore they likely have lower influence on the prioritization of Council goals and plans as compared to full members. This situation not only creates inequities among Focal Points across communes but, perhaps, inequities of ECD services for children and their families across communes.

The combination of policy and interview data also provided rich information about local implementation. For example, assurances from national-level interviews about the adequacy of monitoring systems were sometimes contradicted by observation of the actual implementation and use of monitoring checklists in programmes where some clear features of quality were missing but unaddressed in the instruments. Exclusion of certain groups of children - in particular, those with disabilities or in particularly disadvantaged households - could be observed directly at the local level and then compared to reports and interviews by province or national-level staff.

While each of these countries provides a slightly different aspect to the influence of policy on governance function, an emerging theme that can be extracted from these findings is that countries, by articulating policy provisions for coordination, can potentially have an important impact on ECS. Sometimes these provisions directly address ECS, e.g., Kenya and at other times, indirectly, e.g., Cambodia. Strengthening governance requires an analysis of these policies and resultant institutions because they have the potential, through their directives on coordination, to influence ECS.

\subsection{Local Governance Structures as a Key Lever for ECS Improvement}

Most work on ECD at the policy level has traditionally focused on national or central levels and at service level on the service providers. The lowest (or more local) level of decision makers, who are closest to the points of service delivery, often are not taken into account in any systems of service level analyses of ECD. Our study, through a systematic investigation of all levels of government, revealed the significant role of the local level of government in governance decisions that impacted equity, access and quality. The observations and interviews conducted in the villages with the 
village authorities and parents gave us tremendous insight into the critical role of decision making at this lowest level of governance, which was similar across the countries. We use the data from two countries on the governance of finance to illustrate this point.

In Cambodia, Commune Councils, the chief mechanism of decentralization in governance, are responsible for budgets of Community Preschools, which can represent a substantial proportion of their social service budgets. Decentralized decision-making is reflected in the direct funding of Commune Councils by the Ministry of the Interior through Sangkat funds. Commune-level investment and commitment to early childhood development services thus need to be stressed through the integration into local budgeting priorities. While ECE is one of the four priorities for Commune Council spending guidelines being developed by the Ministry of Investment for expenditure of UNDP social service funds ( $\$ 1,000$ per commune), the ultimate decision on spending rests with the commune chief. Furthermore, commune councils vary a great deal in their willingness to invest even small portions of their social service funds to ECD and often their spending is on infrastructure costs. The limited attention and importance to ECD at the local level is hampering access and equity of ECS. In Kenya, the role of community leaders in the governance of ECS finance is also critical. As per the KESSP for 2005-2012, the allocation of finance is directly to communities. The community leaders and authorities receive the grants, disburse the funds and manage the budgets. Almost $75 \%$ of ECDE funds are distributed directly to communities through grant mechanisms.

Similarly, in LPDR we noted the role of the village chief and local authorities in the quality of educational opportunities for children. An observation of primary schools in three adjacent villages revealed great disparities in school quality, curriculum and teacher motivation. The observations were then supplemented with individual and group interviews with the village leaders. The government covers the basic costs of provision of textbooks and teacher salaries. The remaining funds have to come from the communities. The schools in the poorer communities remain at a disadvantage because they have to rely on their own communities to cover the shortfall. Taking into consideration this initial inequity, the results indicated that in villages where the village chief and primary school principal used a more entrepreneurial approach to governance of finance, the school quality was better. In the first village, which had the poorest quality school, the principal saw his role primarily as management of the day-to-day operations of the school. In contrast, at the school in the next village, which was of far better quality, the principal stated that he saw multiple roles for himself, from fundraising to building solidarity among the teachers. The principal in the second village leveraged the school fees by having teachers create a way to share learning materials. With money freed up, he invested in sustainable long-term projects for the school, such as communications. He then used these communication systems, e.g., phone, to contact families who could send remittances from abroad and thereby increase the revenue even further of the school. The noted difference was in the entrepreneurial management and governance of finance that this second village principal had assigned himself. A teacher in the second village, during the focus group discussion, commented "We have a good school because we have a very good principal", compared to the first principal who did not use creative strategies to extend the funds. These analyses clearly demonstrate that while the system does create inequities, individual efforts at the local level of government can address them. 
The country analyses suggest that while assessments of service design, implementation and budgets are often made at the central level, it is the local level of decision-making that has a significant impact of ECS. The degree to which local level decision makers understand the importance of ECD and the types of service level features that will improve child outcomes to a large extent determines the quality of the services. The results suggest that the ramifications for governance of finance lie within the areas of capacity building of local government. Furthermore, the results from Cambodia suggest that incentivizing spending of commune sangkat funds on ECD might be a useful strategy to consider. To the extent that Cambodia has embraced a cascadedown approach to decentralization and deconcentration and guidelines and benchmarks have not yet been developed for these levels, perhaps these holistic ECD benchmarks and guidelines should be more directly established for Commune Councils to reflect national priorities in local decisionmaking. Where early childhood education services are not being accessed because of other social needs and prioritization of investment in tangible goods, the Commune Councils might explore a wider range of services and better coordination of those services in order to meet their national benchmarks. This requires capacity-building at the local level for governance of ECS, and the development of new roles to implement such capacity building.

\subsection{Role of Beneficiaries in Governance of ECS}

Most work on governance and finance has focused on the supply perspective to services, with less work examining the demand side for these services. Data from the health sector suggests, for example, that the family take-up of services is not just a factor of access and availability, but is also linked with the motivation of families to engage with the system. In ECD, this type of analysis is rare. A significant element of this study was the examination of the beneficiary perspective on ECS and the ramifications of that for increased equity, access and quality. In all three countries, we conducted focus group discussions with families with young children to understand their perception of the services and their role in governance and finance. This is particularly important, because many ECS are funded through some combination of parent fees or in-kind contributions. What our study has revealed is that understanding parental perceptions of ECS is vital. In each country however, parental perceptions and understandings were different.

In Kenya, for example, the parent data revealed a contextual obstacle to the expansion of enrolment in ECD services. The Kenyan government had introduced free primary education since 2003. Preschool and pre-primary programmes however, are fee based. Parents indicated that they skip ECD because they viewed primary education as a core public service and therefore free, ECD less essential because it was not free. The parents' perspective was that if the government thought ECD was essential, it would also offer it free of cost.

In Cambodia, the rates of low enrolment were also linked, in part with parents' perspectives. However these perspectives differed from Kenya. Many parents, for example, did not perceive their children who were small for their age or stunted as being ready to learn or attend ECE programmes, often one of the main reasons that prevented mothers from enrolling their child in the Community-Based Preschools. Another major concern, shared by mothers regarding their children's well-being, was the availability of food. Parents in our focus group reported malnutrition to be their utmost concern and urged some provision of food that will incentivize children to attend preschools. Integration of child nutrition directly into the CPS or HBP programme is 
generally inexistent and most commune councils do not seem to be investing in providing regular snacks or breakfasts for CPS children. If parent perceptions were taking into consideration, then incorporating nutritional services into current ECE models could help expand access.

In LPDR, there have been extensive efforts and funding to improve immunization rates. However, these rates have been increasing very slowly, compared to the investments made in the health sector, and they remain short of the benchmarked targets. Families who do not immunize their children, excluding those who do not have access to even the outreach mobile clinics, are doing so out of choice. The primary reasons in our data for avoiding immunizations were lack of knowledge of its benefits and misinterpretation of the immediate side effects, particularly among the Hmong ethnic minority participants. Parental perceptions very much guide the take up of services. However, as these findings suggest, the LPDR parents had very different understandings of ECS compared to the other countries in the study.

Understanding consumers' preferences and needs is vital to business and the for-profit sector, particularly when it comes to children, the social sector has not accorded it the same attention, with some exceptions (Gassman-Pines, Godfrey, \& Yoshikawa, 2013). Examinations of beneficiary perspectives are quite limited in global ECD, particularly in studies of governance or policy. This study was one of the initial inquiries into the role beneficiary perspective plays in influencing equity, access and quality with implications for governance strategies. This initial examination reveals that beneficiaries are a potential constituency who need to be acknowledged and invited to contribute; however further work is warranted into obtaining more reliable and valid observations of the operationalization of parental participation in governance. This study further indicates that parental perceptions are very different across countries and therefore the role of culture in policy making is potentially critical for ECS, compared to other sectors, (Harkness et al., 2013; Yoshikawa \& Currie, 2011).

\subsection{Closing Issues}

In this final section of the paper, we discuss a series of miscellaneous relevant issues to governance of ECS: (i) for which either we have very little or preliminary data to support our claims; (ii) the sampling of countries limits our ability to provide conclusions; and (iii) our recommendations for future work in this area for ECD.

\section{6.a. Emerging Trends}

For some issues, we started to see emerging trends in the findings that need to be further explored. For example, the role of social protection and child protection in ECS is still unclear - in part due to the brief nature of our in-country visits, we concentrated on health and education, with less emphasis on these other sectors. In Kenya, we were able to examine the social protection mechanism of conditional cash transfer for vulnerable children. However, this sector was not well integrated into the ECD system and the programme did not directly address children under 8 years of age; it was more broadly focused on children. Similarly for child protection, in Cambodia, for example, we started to discern that trends in the integration of children with special needs were at an early stage of development. Strong cultural norms against inclusion exist in many contexts. Some parents of stunted children explained to us that their child was too small to participate in preschool, for example. No national system exists for early childhood intervention for children 
with disabilities, and inclusion of this group therefore does not occur at all consistently in any of the ECD service systems. In LPDR at the systems level, we noted that the sectors of health and education, because of their involvement in ECD, understood their role, however, other relevant sectors such as justice and welfare did not. For example, the justice sector is responsible for children's rights and welfare for child protection. Both of these sectors have intersecting interests, however, our interviews revealed they were unclear about how to operationalize those roles in ECD. Therefore, this initial exploratory study, while presenting a set of potentially clear findings, also suggests that there are many areas that need further inquiry if we are to examine more comprehensively governance and finance of ECS.

\section{6.b. Developing Analysis Tools}

The significance of this study is noted in the triangulation of policy content analyses results with key informant interview results. The joint analysis of multiple sources of information for examining governance of ECS is unique to this particular study. This methodology has also afforded the understanding of particular features and influences of policy on governance of ECS.

We believe that such a mapping of governance functions is an important communication tool, not only for researchers, but for each set of actors within an ECS national system. The analyses of these maps enabled us to identify the bottle-necks and challenges in achieving equity, access and quality. For example, it highlighted the close integration of one of the three preschool systems in Cambodia with local governance and budgeting, and relative lack thereof in the other two systems. It also highlighted the weakness at the provincial or subnational level in cross-sector coordination in each of our countries.

The maps were also useful in highlighting budget flows between the national and local levels. We intended this aspect of the maps to provide the context for more fine-grained analysis of actual budgets. However, in each of the countries, with limited time and resources for our studies, as well as substantial barriers to accessing full and accurate budgeting information, we were unable to complete the final step of linking actual budget figures to the budget flow maps. Nevertheless, the mapping of the governance of finance (how budget flows occur within the policy architecture linking national, subnational and local implementation), we believe, was useful in our analyses in each country.

We hypothesize that these policy architecture maps may be important for the actors themselves to know who else is involved in their area of work and what role these other actors play. Careful analysis of such maps may lead to greater cohesion in governance and reduction of duplicated efforts. Furthermore, we also hypothesize that such maps are useful for the general public, in communities, to help them understand who are the main actors involved with service delivery in their area. This level of communication may serve to increase population-level participation in governance, accountability to beneficiaries or at the very least inform the public of how services are governed in their area. It should be noted that the content of policy and governance maps is determined by focal point consultations, key informant replies, and document searches to which pre-defined criteria are applied (e.g. language, time-frames, document types). By utilizing multiple approaches, biases in the mapping process could be minimized. However, results must be taken with caution as the systems and processes described are dynamic, may vary depending on 
selection criteria of documents and respondents, and need significant iteration from multiple stakeholders.

\section{6.c. Limited Generalizability of Specific Findings across 3 Countries}

The study was conducted in three very different countries. In the sections above, we have provided findings from patterns of similarity and differences that emerged in our cross-country examination. Kenya was the most advanced of the three countries with respect to a history of involvement in ECD. Kenya was the only country in the sample that had passed a child law and an ECD policy. Therefore, the governance issues in Kenya were slightly different. In particular, it afforded us the opportunity to understand the implementation of coordination agencies at national and sub-national levels. Second, Kenya, globally, and in particular in Sub-Saharan Africa is recognized for its high level of government, financial investment in education. Although a majority of the education sector budget is devoted to education, there still is a greater government investment in education spending. These situations were not noted in Cambodia and LPDR. Finally, the mere fact of different geographic regions also differentiated the three countries. Cambodia and LPDR are in South-East Asia and share a lot more in common culturally and regionally compared to Kenya. So establishing cross-country comparisons had to be handled with care without oversimplifying the results and also not overstepping country level issues in interpretation.

Within countries, due to limited time and resources, we were restricted in our ability to sample a wider range of geographic areas, provinces, and villages. Future work in this area would benefit from larger samples of subnational and local level units. Although we ensured consideration of geographic (remoteness; urban/rural; representation of different ethnic and tribal groups) and to some degree capacity dimensions in our sampling, the systematic addition of other sampling criteria was not possible given our limited sample size of provinces and villages.

Finally, our current sample only included low-income countries. In these countries, for example LPDR and Cambodia, the major financial investment in ECS came from international development and donor agencies. As a result, many of the governance decisions at national and sub-national levels were dictated by donor priorities and aims. One of the largest governance issues facing LPDR is coordination with international partners on ECD. Furthermore, in our analyses, often because finance played such a large role, it was difficult to untangle true governance decisions from the governance of finance decisions. If our sample had included middle-income countries, we may have seen a different pattern of results. For example, while Kenya is still a low-income country, because of the large government financial investment in education, we observed a difference in governance decisions, compared to LPDR whose education budget is overwhelmingly supported by international aid.

\section{6.d. Next Steps}

Studying governance and finance in ECD is a novel area. There are aspects of the governance and finance mechanisms that are unique to ECD and present crucial challenges from the beneficiary, service and systems perspective. For instance, children's and parents' perceptions of their needs during the period from birth to age 6 change rapidly, making integration of beneficiary perspectives particularly challenging. For instance, perspectives of parents of infants and toddlers 
cannot be merged with those of parents of pre-primary age children. At the systems and service levels, marginalization of early childhood has typically been noted within the education sector. Funding priorities and access to ECE tend to be lower than, for example, primary education in lowincome countries. In terms of programme or service development, it is difficult to give a single prescription given the very different levels of government investment and commitment to ECS across nations. For example, investment tends to be high in Cambodia, Kenya and Lao PDR. This means the role of international and local NGOs in governance is also very different across these nations. Programmatically, across LMIC countries, there is an age-specific split with health often predominant from antenatal through end of infancy; and education picking up at the pre-primary level. This sectoral division raises challenges for coordination at multiple stages because of assigned stakeholder roles, planning processes, and sector-specific implementation mechanisms.

As data from impact evaluations start to grow and ECS increases in coverage across many LMICs, we need to systematically understand how to strengthen the systems that support these services. There is wide recognition of the interdependency between the factors implicated in system strengthening, such as capacity building, finance and costing, and governance (van Ravens, 2008); nevertheless, governance and finance are critical because of the infrastructure support these processes provide (Kaufmann et al., 2004; World Bank, 2008) and because they profoundly influence the local quality of programmes and ultimately the direction and size of impacts on children's health, learning and behaviour. This study, as an exploratory and early effort to develop methods and analytic approaches to the study of governance, made several methodological contributions, especially in the areas of policy architecture and budget flow mapping as applied to ECS and the simultaneous analysis of vertical and horizontal governance issues in ECS. However, several future directions also became clear in the course of conducting the study.

First, within the horizontal dimensions of governance, our study focused primarily on coordination. Even though it is central to effective ECS, other functions of governance also need to be examined. For example, the results in the study from Kenya indicate that greater attention needs to be paid to the role of data monitoring, assessments and sharing in improving effectiveness and accountability of the system. Similarly, we need to focus more on the types of capacities that are required for governance. Our study suggested that competencies, for example, in middle-level governance at subnational levels are overlooked in leadership development in ECS and perhaps in other social sectors. At that level, many system level informants whom we interviewed do not deliver services, yet make important decisions regarding the quality of the programmes. Therefore, attention needs to be given to understanding capacity and associated competencies in knowledge of system-level decision makers as opposed to capacity in practice of service providers (Hommel, 2013). Included in this inquiry should be an understanding of training and supervision, both pre-service and in-service.

Second, much of our analyses focused on governance with a limited attention to finance for several reasons. The conceptualization of finance and costing for ECS is relatively new. Therefore, we had limited frameworks that could be applied to the analyses. We relied on the existing literature and work in this area (van Ravens, 2010). Second, through our country level work, we also learned that sharing of financial information is not typical. For the most part, such information is not requested in research studies. Therefore obtaining data on costs, financial estimates and generation of funds was difficult. The areas we were able to explore were the governance of finance, i.e., the roles, 
responsibilities and decisions on disbursement of funding. The national and sub-national level informants shared with us their process of decision making. The actual numbers on the costs and funds themselves were difficult to ascertain.

Third, in our work we started to develop policy architecture maps in each of the three countries. In each country the maps emphasized slightly different aspects of the policy, system and service. This was in part due to the unique policy environments of each country, and in part due to the fact that we were developing methodology in an area that has few accepted conventions. For example, a strength of the policy maps in Cambodia allowed for a presentation the policy architecture for each of several ECS service programmes (three in preschool education and one in health), enabling a comparison of the services and ability to generate recommendations to improve the governance and finance mechanisms. Budget flows were integrated with supervisory and monitoring links in this map - this enabled identification of the most salient differences across parallel systems, such as the three preschool education systems in the country. This map also captured how the national process of decentralization and devolution affected ECS delivery in the country.

In Lao DPR, on the other hand, the static map could be considered a strength in that it visually demonstrated the complexity of the totality of ECS actors and their roles in ECD. It could therefore provide a holistic indicator of slow progress in ECS. Given that the diversity of actors would need to coordinate and that the policies they follow are disparate, achieving coordination in governance and finance could be a challenge. The advantage of this policy architecture map is that it allows for the representation of all actors and documents linked with ECS and the ability to indicate their relationships. This is useful for countries where there are many actors in ECD.

In Kenya, policy and governance maps provided an illustration of the governance roles of the main entities in ECS as designed by a national framework. Upon mapping the architecture, fidelity to this design was tested via the semi-structured interviews. This mapping technique can provide a blueprint for the country to follow in the implementation of ECS. A strength of this technique is that they may enable a detailed understanding of the governance functions. The results of this study suggest that mapping the policy architecture is an important tool for the field of ECD which can be used for analysis of complex processes. A next step could be to determine useful features of policy architecture maps for ECD and their relevance for countries based on GNI, investment in $E C D$, nature of policies, and diversity of actors.

Fourth, from a methodological perspective, future work needs to allow for greater time within countries for a more in-depth analysis of the situation - particularly, more exploration of the horizontal dimension of geographic and population-level comparison of governance. The 10-14 day country visits were short, and allowed sampling of only 2 local contexts in addition to the capital (typically, rural and remote). While the agenda during the visits was full, given the logistics of travel time, delays in starting interviews and the need for translation limited the progress of the study. Therefore, more intensive, multi-site in-country visits are suggested for future work analyzing both vertical and horizontal dimensions of governance. However, the current phases of content analysis of the policy, and ECD situation in the country worked well and should be continued to inform the in-country visit. The key collaboration between the international and local study teams was also a factor in the success and should be retained in any study of country governance. 
In conclusion, this initial exploratory and primarily qualitative study examining the governance and finance of ECS in low-income countries was a strong start for a new and important area of work. This study offered innovative methodologies and tools, built on the literature of governance and finance to understand how to improve access, quality and equity of ECS. The findings of this study have implications for strengthening systems of ECS and research. 


\section{REFERENCES}

Abt Associates (2011). Health systems 20/20: Eight strategies that strengthen health systems. Bethesda, MD.

Abagi, O. (2008). Early childhood development and education situation analysis report. Government of Kenya /UNICEF.

Arts, W., \& Gelissen, J. (2002). Three worlds of welfare capitalism or more? A state-of-the-art report. Journal of European Social Policy, 12, 137-158.

Baker-Henningham H., Walker S., Powell C., \& Gardner J.M. (2009). A pilot study of the Incredible Years Teacher Training program and a curriculum unit on social and emotional skills in community preschools in Jamaica. Child Care Health and Development, 35(5), 624-31. Epub 2009 Mar 23.

Baldacci, E., Clements, B., Gupta, S., \& Cui, Q. (2008). Social spending, human capital, and growth in developing countries. World Development, 36(8), 1317-1341.

Barnes, C., Gaile, G., \& Kimbombo, R. (2001. Impact of three microfinance Programs in Uganda. Washington, DC: US Agency for International Development.

Barnes, C., Keigh, E., \& Nemarundwe, N. (2001). Microfinance program clients and impact: an assessment of Zambuki Tust, Zimbabwe. AIMS Paper. Washington, D.C.: Management Systems International.

Belfield, C. (2006). Financing early childhood care and education: An international review. Paper commissioned for the Education for All Global monitoring Report, 2007: Strong Foundations: Early Childhood Care and Education. Paris: United Nations Educational, Scientific and Cultural Organization.

Berlinski, S., \& Galiani, S. (2007). The effect of a large expansion of pre-primary school facilities on preschool attendance and maternal employment. Labor Economics, 14, 665-680.

Bhutta, Z.A., Sajid, S., \& Zahid, M. (2008). Training for Lady Health Workers clarified. Bulletin of the World Health Organization, 86 (12), B.

Bornstein, M.H., Britto, P.B., Nonoyama-Tarumi, Y., Ota, Y., Petrovic, O., \& Putnick, D.L. (2012). Child development in developing countries: Introduction and methods. Child Development, 83(1), 16-31.

Bowman, B., Donovan, M.S., \& Burns, M.S. (2001). Eager to learn: Educating our preschoolers. Washington, DC: National Research Council.

Britto, P.R., Cerezo, A., \& Ogbunugafor, B. (2008). National ECD policy development: Case study from the People's Democratic Republic of Lao. International Journal of Early Childhood, 40, 101-118.

Britto, P.R., Engle, P.E., \& Super, C.S. (Eds.) (in press). Handbook of early child development research and its impact on global policy. New York, NY: Oxford University Press.

Britto, P. R. \& Kagan, S. L. (2010). Global status of early learning and development standards. In P. Peterson, E. Baker, \& B. McGaw, (Eds.), International encyclopedia of education, Vol. 2 (138143). Oxford, UK: Elsevier. 
Britto, P. R., Yoshikawa, H., \& Boller, K. (2011). Quality of early childhood development programs in global contexts: Rationale for investment, conceptual framework and implications for equity. Social Policy Report Vol. 25, No. 2. Washington, DC: Society for Research in Child Development.

Britto, P. R., Ulkuer, N., Hodges, W. P., \& McCarthy, M. F. (2013). Global Policy Landscape and Early Child Development. In P. Britto, P. Engle, \& C. Super (Eds.), Handbook of Early Childhood Development Research and Its Impact on Global Policy (pp. 65-81). Oxford: Oxford University Press.

Bronfenbrenner, U. (1979). The Ecology of Human Development: Experiments by nature and design. Cambridge, MA: Harvard University Press.

Burnside, C., \& Dollar, D. (2000). Aid, policies and growth. American Economic Review 90, 847-868.

Cai, Y., \& Feng, X. (2007). Reconstruction of the financial system in early childhood education in China. Frontiers of Education in China, 2, 250-258.

Chawla, L. (Ed.). (2002). Growing up in an urbanising world. London: Earthscan Publications.

Dahlberg, G., Moss, P., \& Pence, A. (2007). Beyond quality in early childhood education and care: Languages of evaluation ( $2^{\text {nd }}$ edition). London: Routledge.

de Guzman, A. B. (2007). Chronicling decentralization initiatives in the Philippine basic education sector. International Journal of Educational Development, 27(6), 613-624.

Delamonica, E., Mehrotra, S., \& Vandemoortele, J. (2004). Education for All: How much will it cost? Development \& Change, 35(1), 3-30.

Duke, T. (2004). Inequity in child health: What are the sustainable Pacific solutions? Medical Journal of Australia, 181(11-12), 612-614.

Engle, P. L., Fernald, L. C., Alderman, H., Behrman, J., O'Gara, C., Yousafzai, A., de Mello, M.C., Hidrobo, M., Ulkuer, N., Ertem I., Iltus S., \& The Global Child Development Steering Group. (2011). Strategies for reducing inequalities and improving developmental outcomes for young children in low-income and middle-income countries. The Lancet, 378(9799), 1339-1353.

Esping-Andersen, G. (1990). The three worlds of welfare capitalism. Cambridge, UK: Blackwell Publishing Ltd.

Gassman-Pines, A., Godfrey, E. B., \& Yoshikawa, H. (2013). Parental goals moderate the effects of welfare policies on children: A person-environment fit approach. Child Development, 84, 198208.

Gertsch, L., (2009). Getting the basics right: Contribution of early childhood development to quality, equity and efficiency in education. Eschborn, Germany: GTZ.

Godfrey, M., Sophal, C., Kato, T., Vou Piseth, L., Dorina, P., Saravy, T., Savora, T., \& Sovannarith, S. (2002). Technical assistance and capacity development in an aid-dependent economy: The experience of Cambodia. World Development, 30(3), 355-373.

Heckman, J.J. (2012). The power of the early years: Creating and measuring capabilities. Beijing, China: Human Capital and Economic Opportunity Global Working Group. 
Hodgkin, R., \& Newell, P. (2007). Implementation handbook for the Convention on the Rights of the Child. Geneva, Switzerland: UNICEF.

International Step-by-Step Association (2005). ISSA pedagogical standards for preschool and the primary grades. Budapest.

Irwin, L. B., Siddiqui, A., \& Hertzman, C. (2007). ECD: A powerful equalizer. Geneva, Switzerland: World Health Organization.

Jones, H. (2009). Equity in development: Why it is so important and how to achieve it. ODI Working Papers 311.

Kamerman, S.L. (2000). Early childhood education and care: An overview of developments in OECD countries. International Journal of Educational Research, 33, 7-29.

Kaufmann, D., Kraay, A., \& Mastruzzi, M. (2004). Governance matters III: Governance indicators for 1996, 1998, 2000, and 2002. The World Bank Economic Review, 18(2), 253-287.

Kaul, V., \& Sankar, D. (2009). Early childhood care and education in India: Education for All - Middecade assessment. New Delhi, India: National University of Educational Planning and Administration.

Kenya National Bureau of Statistics, 2009. Kenya Facts and Figures.

Khattab, M.S. (1995). A comprehensive review of the status of early childhood development in the Middle East and North Africa. Study prepared for the Education Section of UNICEF/Middle East and North Africa Regional Office, Amman, Jordan.

Lokshin, M.M., Glinskaya, E., \& Garcia, M. (2000). The effect of early childhood development programs on women's labor force participation and older children's schooling in Kenya. Working Paper 2376. Washington DC: World Bank.

Levy, S. (2006). Progress against poverty: Sustaining Mexico's Progresa-Oportunidades program. Washington, DC: Brookings Institution.

Manzi, F., Schellenberg, J. A., Adam, T., Mshinda, H., Victora, C. G., \& Bryce, J. (2005). Out-ofpocket payments for under-five health care in rural southern Tanzania. Health Policy and Planning, 20(S1), i85-i93.

McCartney, K., \& Phillips, D.A. (Eds.). (2006). Handbook of early childhood development. Oxford, UK: Blackwell Publishing.

Ministry of Interior (MOI) \& UNICEF Cambodia (2009). CCWC Capacity Assessment. Phnom Penh, Cambodia: Ministry of Interior, UNICEF Cambodia, and VBNK.

Myers, R.G. (1995). The twelve who survive: Strengthening programs of early childhood development in the third world. ( $2^{\text {nd }}$ ed.). Ypsilanti, MI: High/Scope Press.

Myers, R.G. (2006b). Quality in programs of early childhood care and education. Background paper prepared for Education for All Global Monitoring Report 2007. Starting strong: Early childhood care and education.

Myers, R., \& de San Jorge, X. (1999). Child care and early education services in low-income communities of Mexico City: Patterns of use, availability, and choice. Latin America and Caribbean Regional Office: World Bank. 
Naudeau, S., Kataoka, N., Valerio, A., Neuman, M. J., \& Elder, L. K. (2011). Investing in young children: An early childhood development guide for policy dialogue and project preparation. Washington, DC: World Bank.

Olmsted, P.P. (2002). Data collection and system monitoring in early childhood programs. UNESCO Early Childhood and Family Policy Series $\mathrm{n}^{\circ} 5$.

Pence, A. (2004). ECD policy development and implementation in Africa. Paris: UNESCO.

Pronyk, P.M., Hargreaves, J.R., Kim, J.C, Morison, L.A., Phelta, G., Watts, C., Busza, J., \& Porter, J.D. (2006). Effect of a structural intervention for the prevention of intimate partner violence and HIV in rural South Africa: A cluster randomized trial. The Lancet 368, 1973-1983.

Rajkumar, A.S. \& Swaroop, V. (2008). Public spending and outcomes: Does governance matter? Journal of Development Economics, 86, 96-111.

Rayna, S. (2003). Implementation of the integrated early childhood policy in Senegal. Early Childhood and Family Policy Series No.2. Paris: UNESCO.

Roberts, M., Hsiao, W., Berman, P., \& Reich, M. (2008). Getting health reform right: A guide to improving performance and equity. New York: Oxford University Press.

Rolla San Francisco, A., Arias, M., Villers, R., \& Snow, C.E. (2006). Evaluating the impact of different early literacy interventions on low-income Costa Rican kindergarteners. International Journal of Educational Research, 45, 188-201.

Rutter, M. (2002). Nature, nurture, and development: From Evangelism through science toward policy and practice. Child Development, 73, 1-21.

Sachs, J.D. (2004). Health in the developing world: achieving the Millennium Development Goals. Bulletin of the World Health Organization, 82, 947-952.

Schellenberg, J.A., Victora, C.G., Mushi, A., de Savigny, D., Schellenberg, D., Mshinda, H., \& Bryce, J. (2003). Inequities among the very poor: Health care for children in rural southern Tanzania. The Lancet, 361(9357), 561-566.

Sharma, A., Sharma Sen, R., \& Gulati, R. (2008). Early childhood development policy and programming in India: Critical issues and directions for paradigm change. International Journal of Early Childhood, 40(2), 65-83.

Shmis, T. (2010). Early childhood quality initiatives: Six Russian regions. World Bank/UNESCO policy review. Presented at the UNESCO World Conference on ECCE, Moscow, September.

Shonkoff, J.P., \& Phillips, D.A. (2000). From neurons to neighborhoods: The science of early childhood development. Washington, DC: National Academy Press.

Super, C.M., \& Harkness, S. (1999). The environment as culture in developmental research. In T. Wachs \& S. Friedman (Eds.), Measurement of the environment in developmental research (279-323). Washington, DC: American Psychological Association.

Tobin, J., Hsueh, Y., \& Karasawa, M. (2009). Preschool in three cultures revisited: China, Japan, and the United States. Chicago: University of Chicago Press.

United Nations Children's Fund. (2002a). Facts for life. New York, NY: UNICEF, WHO, UNESCO, UNFPA, UNDP, UNAIDS, WFP, and World Bank. 
United Nations Children's Fund: World Fit for Children. (2002b). Special session on children. New York: UNICEF.

United Nations Children's Fund. (2008). The child care transition: A league table of early childhood education and care in economically advanced countries. Florence: UNICEF Innocenti Research Centre.

United Nations Children's Fund. (2012). Inequalities in early childhood development: What the data say. New York, NY: UNICEF.

United Nations Children's Fund Cambodia. (2010d). Oddar Meanchey ECD Quarterly Report January-March 2010. UNICEF Cambodia Oddar Mean Chey Office.

United Nations Educational, Scientific and Cultural Organization, 2006. EFA Global Monitoring Report: Strong Foundations. Paris, UNESCO.

United Nations Educational, Scientific and Cultural Organization. (2006). Strong foundations: Early childhood care and education. EFA Global Monitoring Report 2007. Paris, France: UNESCO.

United Nations Educational, Scientific and Cultural Organization. (2007). EFA global monitoring report, 2007: Strong foundations - Early childhood care and education. Paris, France: UNESCO.

UNDP (1999). Decentralization: A sampling of definitions. Working Paper.

Vargas- Barón, E. (2005). Planning policies for early childhood development: Guidelines for action. UNESCO.

Vargas-Barón, E. (in press). Building and strengthening national systems for early childhood development. In P.R. Britto, P.E. Engle, \& C.S. Super (Eds.), Handbook of early child development research and its impact on global policy. New York, NY: Oxford University Press.

Vegas, E., Aran, M., \& Jelamschi, L. (2010). A policy framework for early childhood development and its application to Turkey. Washington, DC: World Bank

Vogler, P., Crivello, G., \& Woodhead, M. (2008). Early childhood transitions research: A review of concepts, theory, and practice. Working Paper 48. The Hague, The Netherlands: Bernard van Leer Foundation.

Walker, S., Chang, S., Powell, C., \& Grantham-McGregor, S., (2005). Effects of early childhood psychosocial stimulation and nutritional supplementation on cognition and education in growth-stunted Jamaican children: prospective cohort study. The Lancet, 366: 1804-1807.

Wilkinson, R., \& Pickett, K. (2009). The spirit level: Why greater equality makes societies stronger. London: Bloomsbury Press.

Woodhead, M., Ames, P., Vennam, U, Abebe, W., \& Streuli, N. (2009) Equity and quality?: Challenges for early childhood and primary education in Ethiopia, India and Peru. Working Paper No. 55, Studies in Early Childhood Transitions. The Hague, The Netherlands: Bernard van Leer Foundation.

World Bank. (2006). Global monitoring report. Washington, DC: Author.

World Bank. (2008). Kenya Poverty and Inequality Assessment. Volume 1: Synthesis Report. World Bank Africa Region, Poverty Reduction and Economic Management Unit. 
World Health Organization. (1999). The critical link: Interventions for physical growth and psychological development. Geneva, Switzerland: WHO.

World Health Organization (2007). Everybody's business: Strengthening health systems to improve health outcomes. WHO's framework for action. Geneva, Switzerland: WHO.

Yoshikawa, H., \& Currie, M. (2011). Culture, public policy, and child development. In X. Chen \& K. Rubin (Eds.), Culture and Children's Socio-Emotional Development. New York: Guilford Press.

Yoshikawa, H., Rosman, E.A., \& Hsueh, J. (2002). Resolving paradoxical criteria for the expansion and replication of early childhood care and education programs. Early Childhood Research Quarterly, 17, 3-27.

Zigler, E.F., \& Hall, N.W. (2000). Child development and social policy: Theory and applications. New York: McGraw-Hill. 
UNICEF

Office of Research

UNICEF Office of Research

Piazza SS. Annunziata, 12 50122 Florence, Italy

Tel: +39055 20330

Fax: +39055 2033220

florence@unicef.org

www.unicef-irc.org

๑) The United Nations Children's Fund (UNICEF) 